\title{
Development and Research Status of Tidal Current Power Generation Systems in China
}

\author{
Hao Chen ${ }^{1}\left(\mathbb{D}, \mathrm{Qi} \mathrm{Li}^{1}{ }^{1}\right.$, Mohamed Benbouzid $^{2, *}{ }^{(\mathbb{D}}$, Jingang Han ${ }^{1}\left(\mathbb{D}\right.$ and Nadia Aït-Ahmed ${ }^{3}(\mathbb{D})$ \\ 1 The Research Institute of Power Drive and Control, Shanghai Maritime University, Shanghai 201306, China;

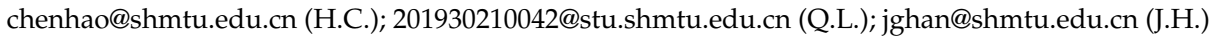 \\ 2 Institut de Recherche Dupuy de Lôme (UMR CNRS 6027 IRDL), University of Brest, 29238 Brest, France \\ 3 Institut de Recherche en Energie Electrique de Nantes Atlantique, University of Nantes, 44602 Saint-Nazaire, \\ France; nadia.ait-ahmed@univ-nantes.fr \\ * Correspondence: Mohamed.Benbouzid@univ-brest.fr
}

Citation: Chen, H.; Li, Q.;

Benbouzid, M.; Han, J.; Aït-Ahmed,

N. Development and Research Status of Tidal Current Power Generation Systems in China. J. Mar. Sci. Eng. 2021, 9, 1286. https://doi.org/ $10.3390 /$ jmse 9111286

Academic Editor: Rosemary Norman

Received: 29 September 2021

Accepted: 13 November 2021

Published: 18 November 2021

Publisher's Note: MDPI stays neutral with regard to jurisdictional claims in published maps and institutional affiliations.

Copyright: (c) 2021 by the authors. Licensee MDPI, Basel, Switzerland. This article is an open access article distributed under the terms and conditions of the Creative Commons Attribution (CC BY) license (https:// creativecommons.org/licenses/by/ $4.0 /)$.

\begin{abstract}
Considering the depletion of oil, coal, gas and other fossil energy, and the increasingly serious environmental pollution, all countries in the world are developing clean and renewable energy, such as wind energy, water energy, solar energy, etc., to alleviate the current energy crisis. Tidal current energy belongs to the marine renewable energy. It is clean, pollution-free, and abundant, with a good prospect of development due to its similarity with wind energy. This paper firstly analyses the reserves and distribution of tidal current energy in China. Then the early exploration of Tidal Current Power Generation System (TCPGS) in China is briefly introduced. Subsequently, it gives the details of the devices and experimental platforms of TCPGS that were researched and developed by various universities, research institutes and enterprises in China. The information mainly includes: the size and the capacity of the system, the support structure, turbine type, the selection of generator, and some river and offshore test information, etc. Finally, it discusses the similarities and differences between China and other countries in tidal current power generation technology, and summaries the current development status and gives the prospect of the TCPGS technology in China.
\end{abstract}

Keywords: tidal current energy; tidal current turbine; China; energy resource; up-to-date review

\section{Introduction}

China is situated in the west coast of the Pacific with a coastline of $18,000 \mathrm{~km}$ (this value should be $32,000 \mathrm{~km}$ if including all the islands). With abundant tidal current energy resources, it has great development potential. TCPGS is similar to the wind power generation system. However, the density of seawater is about 800 times that of air. Therefore, its energy density is very high in spite of its relatively low-flow velocity. At the same flow velocity and installed capacity, the size of TCPGS device is only $1 / 28$ of that of the wind power generation system, indicating that tidal current energy has a very great development value $[1,2]$.

In fact, some countries in the world have started the research on tidal turbine technology, such as the introduction of several industrialized large TCPGS in the literature [3].

Although the experiment of TCPGS has been conducted for a long time in China, it has been in the stage of folk research for a long time. It was not until the early 1980s that universities and research institutes began to dabble in this field. In the 21st century, the research of TCPGS in China has entered a period of rapid development. The number of participating units and research results has increased significantly. Especially since 2010, under the support of the Special Fund Program for Marine Renewable Energy (SFPMRE) in China, some colleges and universities, such as Harbin Engineering University (HEU), Northeast Normal University (NENU), Zhejiang University (ZJU), Ocean University of China (OUC), Dalian University of Technology (DUT), as well as some research institutes, 
companies, and shipyards, such as National Ocean Technology Centre (NOTC), and Harbin Electric Machinery Co., Ltd. (HEC) (Harbin, China). More than 50 units are involved in the research and development of TCPGS [4,5].

At present, China has made great progress in the design methods, key technologies, and device research of TCPGS. HEU, NENU, ZJU, OUC and other colleges and universities have developed more than 10 experimental devices with a vertical-axis and horizontal-axis, $100 \mathrm{~W} \sim 600 \mathrm{~kW}$ rated power, and floating and bottom-mounted fixation technologies [5]. Hangzhou LHD Lin Dong Ocean Energy Technology Co., Ltd. (LHD) (Hangzhou, China) has been developing the "7.5 MW LHD large modular marine tidal current power generation set" project. The 1.7 MW power generation module of the first stage 3.4 MW power generation platform successfully connected to the grid, marking that China's TCPGS has entered "the megawatts era".

Many review papers introduce the tidal current power generation system in China. The literature of $[6,7]$ mainly introduces the tidal current power generation devices studied by several universities in China, and discusses the challenges and development opportunities of tidal current energy utilization in China. The literature of [8,9] focuses on the comparative analysis of the characteristics and technical parameters of different types of tidal current power generation devices, briefly summarizes the installation and operation of tidal current energy demonstration power stations in China, and discusses the types of devices and layout forms. The literature of [10] mainly introduces the recent development of tidal current and wave energy power generation in western countries and China by comparison. Some countries are chosen to compare with China in resource assessment, research and development, and policy aspects. Moreover, some suggestions are given to improve the development of tidal current and wave energy technology. However, the above literature is not comprehensive enough to summarize the research on tidal current power generation in China, or lacks specific project parameters and experimental data. In addition, these papers do not systematically compare with solutions and technical routes of some foreign projects.

This paper first introduces the reserves and distribution of tidal current energy resources in China, and then introduces the TCPGSs in China, and gives more detailed information, such as project parameters and experimental data, which can provide some guidance for scholars in the future design. Finally, it discusses the similarities and differences between China and other countries in tidal current power generation technology, summarizes the situation of tidal current power generation and discusses the development direction of tidal current power generation in China in the future.

\section{Reserves and Distribution of Tidal Current Energy Resources in China}

Up to now, China has conducted three large-scale national tidal current energy resources surveys. They are: Chinese coastal rural marine energy resources regionalisation carried out by the Ministry of Water Conservancy and Electric Power (MWCEP) and the State Oceanic Administration (SOA) in 1986; comprehensive marine investigation and assessment in China (908 special program) launched by SOA in 2004; and a resource survey and selection of key marine renewable energy development and utilisation zones carried out by SOA in 2010. It should be noted that although the tidal current was one of the primary focuses, these assessments also targeted the tidal range, ocean waves, and several other marine renewable energy sources [11].

According to the statistical results of 130 channels along China's coast in the coastal rural marine energy resources regionalization completed in 1989, the theoretical average power of coastal tidal current energy resources in China is about $14 \mathrm{GW}$, but the spatial distribution is very uneven, as shown in Tables 1 and 2 [12]. 
Table 1. Tidal current energy resource reserves of several provinces in 1986 national assessment $[12,13]$.

\begin{tabular}{cccc}
\hline Provinces or Regions & The Number of Channel & Average Power/MW & Proportion/\% \\
\hline Liaoning & 5 & 1130.47 & 8.1 \\
Shandong & 7 & 1177.91 & 8.4 \\
Yangtze Estuary & 4 & 304.88 & 2.2 \\
Zhejiang & 37 & 7090.28 & 51 \\
Fujian & 19 & 1280.49 & 9.1 \\
Taiwan & 35 & 2282.50 & 16.3 \\
Guangdong & 16 & 376.56 & 2.7 \\
Guangxi & 4 & 23.08 & 0.2 \\
Hainan & 3 & 282.35 & 2 \\
\hline Total & 130 & 13948.52 & 100 \\
\hline
\end{tabular}

Table 2. Channel statistics of high energy current density along the coast of China in 1986 national assessment [12].

\begin{tabular}{|c|c|c|}
\hline Regions & The Name of Channel & $\begin{array}{c}\text { The Average Stream Density } \\
\text { of Energy }\left(\mathrm{kW} / \mathrm{m}^{2}\right)\end{array}$ \\
\hline \multirow{2}{*}{ Bohai Strait } & Laotieshan Channel & 17.41 \\
\hline & $\begin{array}{l}\text { North of Beichenghuang } \\
\text { Island }\end{array}$ & 13.69 \\
\hline Yangtze Estuary & $\begin{array}{c}\text { North Harbor of Yangtze } \\
\text { River Estuary }\end{array}$ & 10.3 \\
\hline \multirow{4}{*}{ Zhejiang } & North of Hangzhou Bay & 28.99 \\
\hline & Jintang Channel & 25.93 \\
\hline & Guishan Channel & 23.89 \\
\hline & Xihoumen Channel & 19.09 \\
\hline Fujian & $\begin{array}{c}\text { Northwest of Sandu Cape in } \\
\text { Sandu'ao Port }\end{array}$ & 15.11 \\
\hline Taiwan & Southwest of Yuwong Island & 13.69 \\
\hline
\end{tabular}

It can be seen from Table 1 that Zhejiang Province has the largest number of coastal channels; up to 37 channels. The capacity of tidal current energy is also the most abundant at 7.14 GW, accounting for more than half of the total tidal current energy resources in China. The most interesting positions are mainly concentrated in Hangzhou Bay and Zhoushan Islands [14]. Taiwan, Fujian, Shandong, and Liaoning, with a total of 5.9 GW, account for about $42 \%$ of the nationwide reserves. The tidal current energy reserves of other provinces are relatively small. According to Table 2, the channels of Zhejiang have the best development prospects, such as North of Hangzhou Bay $\left(28.99 \mathrm{~kW} / \mathrm{m}^{2}\right)$, Jintang Channel $\left(25.9 \mathrm{~kW} / \mathrm{m}^{2}\right)$, Guishan Channel $\left(23.9 \mathrm{~kW} / \mathrm{m}^{2}\right)$, and Xihoumen Channel $\left(19.1 \mathrm{~kW} / \mathrm{m}^{2}\right)$, followedfollowed by Laotieshan Channel of Bohai Strait and Sandu'ao of Fujian [15].

In the second national assessment "comprehensive marine investigation and assessment in China" in 2004, a total of 99 channels along China's coastline were chosen, and the tidal current resources were evaluated with the Princeton Ocean Model (POM)-based numerical simulations. The results showed that the tidal current energy power of the main offshore waterways in China ( 99 waterways) are $8.33 \mathrm{GW}$, the technically exploitable installed capacity is $1.66 \mathrm{GW}$, and the technically exploitable annual power generation is $1.46 \times 10^{10} \mathrm{kWh}$. Table 3 shows tidal current energy resource reserves of provinces and Figure 1 shows average power density distribution during the spring tide in the 2004 national resource assessment [16]. 
Table 3. Tidal current energy resource reserves of several key provinces in 2004 national assessment [16].

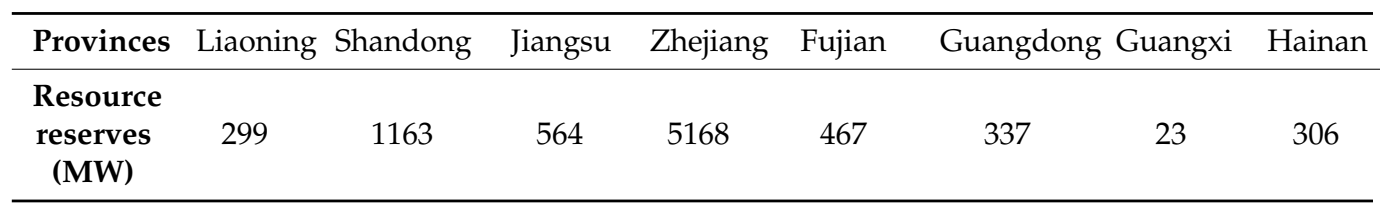

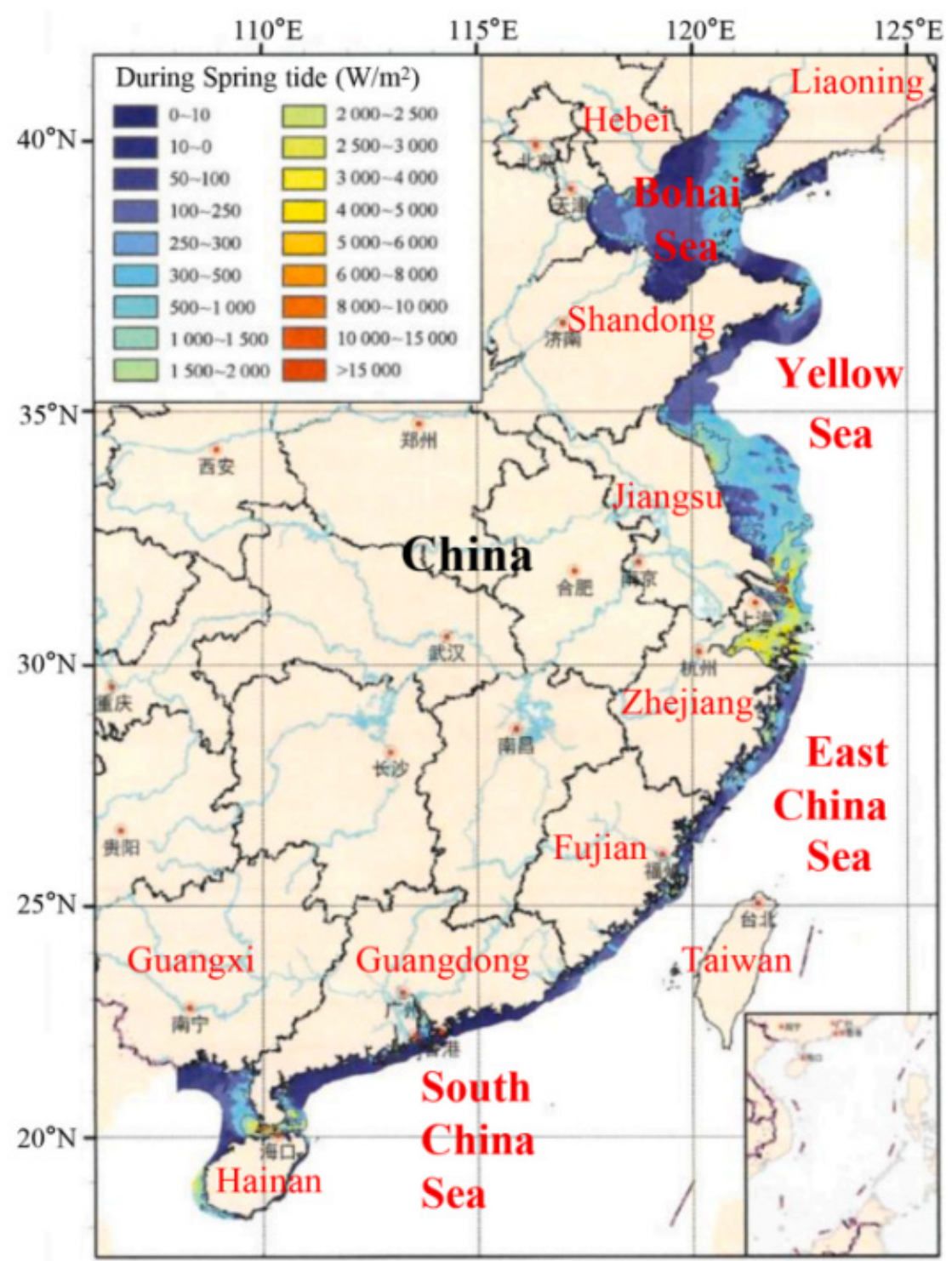

Figure 1. Average power density distribution during spring tide in 2004 national resource assessment. Reproduced from [11], Elsevier.

It can be seen from Table 3 and Figure 1 that Zhejiang Province has the most abundant tidal energy resources, about $5.17 \mathrm{GW}$, accounting for $60 \%$ of the national reserves, followed by Shandong, Jiangsu, Fujian, Guangdong, Hainan, and Liaoning Provinces.

In the following special fund projects for marine renewable energy in 2010, on the basis of the previous projects, 10 key sea areas with 75 channels, including Bohai Strait, Chengshan Cape, Jiaozhou Bay, Zhaitang Island, Yangtze Estuary, Hangzhou Bay, Zhoushan Archipelago, Sansha Bay, Kinmen Archipelago and Qiongzhou Strait were further assessed through Finite-Volume Community Ocean Model numerical simulations combined with on-site survey data. The results show that the theoretical reserve of tidal current energy resources of the 75 channel sections is about $5.56 \mathrm{GW}$, the theoretical annual 
power generation is $4.87 \times 10^{10} \mathrm{kWh}$, the technically exploitable capacity is $8.19 \times 10^{5} \mathrm{~kW}$, and the annual power generation is $7.17 \times 10^{5} \mathrm{kWh}$. Moreover, the utilisation area for each region was evaluated as listed in Table 4 , which was based on the peak power density $\mathrm{P}_{\mathrm{m}}$ rankings, i.e., Class A: $P_{m} \geq 8.0 \mathrm{~kW} / \mathrm{m}^{2}$, Class B: $8.0 \mathrm{~kW} / \mathrm{m}^{2}>P_{m} \geq 4.0 \mathrm{~kW} / \mathrm{m}^{2}$, Class C: $4.0 \mathrm{~kW} / \mathrm{m}^{2}>\mathrm{Pm}>0.8 \mathrm{~kW} / \mathrm{m}^{2}[11]$.

Table 4. Tidal current energy resource reserves of several key regions in 2010 national assessment [11].

\begin{tabular}{|c|c|c|c|c|}
\hline No. & Key Regions & Class A $\left(\mathrm{km}^{2}\right)$ & Class B $\left(\mathrm{km}^{2}\right)$ & Class C $\left(\mathrm{km}^{2}\right)$ \\
\hline 1 & Bohai Strait & 0.0 & 1.0 & 41.2 \\
\hline 2 & Chengshan Cape & 0.0 & 1.2 & 27.8 \\
\hline 3 & Jiaozhou Bay & 0.0 & 0.0 & 4.5 \\
\hline 4 & Zhaitang Island & 0.0 & 0.0 & 0.0 \\
\hline 5 & Yangtze Estuary & 0.0 & 0.0 & 3263.5 \\
\hline 6 & Hangzhou Bay & 0.0 & 0.0 & 486.3 \\
\hline 7 & $\begin{array}{l}\text { Zhoushan } \\
\text { Archipelago }\end{array}$ & 31.4 & 160.4 & 7808.8 \\
\hline 8 & Sansha Bay & 5.2 & 21.0 & 256.8 \\
\hline 9 & $\begin{array}{c}\text { Kinmen } \\
\text { Archipelago }\end{array}$ & 0.0 & 0.0 & 3.8 \\
\hline 10 & $\begin{array}{l}\text { Qiongzhou } \\
\text { Strait }\end{array}$ & 0.0 & 0.0 & 1769.0 \\
\hline \multicolumn{2}{|c|}{ Sum } & 36.6 & 183.6 & $13,670.7$ \\
\hline & All & & $13,890.9$ & \\
\hline
\end{tabular}

According to the above three national resource evaluations, although the evaluation results of the same region are different, it is certain that the total tidal current energy reserves in China are considerable, especially the waters near Zhoushan Islands in Zhejiang Province, which have the most abundant tidal current energy resources reserves, accounting for more than half of the national resources. In addition, some public welfare open tidal current power generation test sites have been built in the waters around the Zhoushan Islands. A lot of the experiments on tidal current power are conducted there, further laying the foundation for the development of large-scale tidal current power generation fields in China.

\section{Current Situation of Research in China}

\subsection{Early Research}

As early as the end of the 1950s, China had already started the experiment of tidal current power generation. In 1958, the Bureau of Hydropower in Shunde, Guangdong province developed a TCPGS. The length and diameter of the turbine rotor are $4.5 \mathrm{~m}$ and $0.6 \mathrm{~m}$, respectively. The device was tested under the Guipanhai sluice, and generated electricity at the water velocity of $1 \mathrm{~m} / \mathrm{s}$ with $700 \mathrm{~W}$ [17].

In winter of the same year, Water Resources Research Institute of Shandong province carried out a TCPGS test in Xiekouwan, Rongcheng, Shandong province. A total of two turbines with $0.8 \mathrm{~m}$ in diameter and $2.78 \mathrm{~m}$ in length were installed on two connected ships, which were connected to a $5 \mathrm{~kW}$ generator by a speed increasing device. Due to the small flow velocity and low transmission efficiency, the voltage generated was less than $220 \mathrm{~V}$ when the water velocity was $0.8 \sim 0.9 \mathrm{~m} / \mathrm{s}$ [17].

In 1969, Jiangsu Yangtze River Hydropower Research Group developed three propellertype tidal current power generation devices with diameter of $5 \mathrm{~m}$. These devices increased speed through hydraulic transmission and gearbox. A total of two barges with power generation devices were anchored to the piers of Nanjing Yangtze River Bridge for the experiment. When the velocity of the water reached $1.3 \mathrm{~m} / \mathrm{s}$, the no-load speed of the propeller was $15 \mathrm{rpm}$ and the instantaneous power was $7 \mathrm{~kW}$, and the total efficiency reached up to $30 \%$ [17]. 
In 1979, He Shijun developed a TCPGS prototype with a propeller-type turbine and hydraulic transmission (see in Figure 2). It was installed on the tail of the fishing boat and tested 21 times in Xihoumen Channel of Zhoushan Archipelago. When the water velocity was $3 \mathrm{~m} / \mathrm{s}$, the power could reach $5.7 \mathrm{~kW}$ [18].

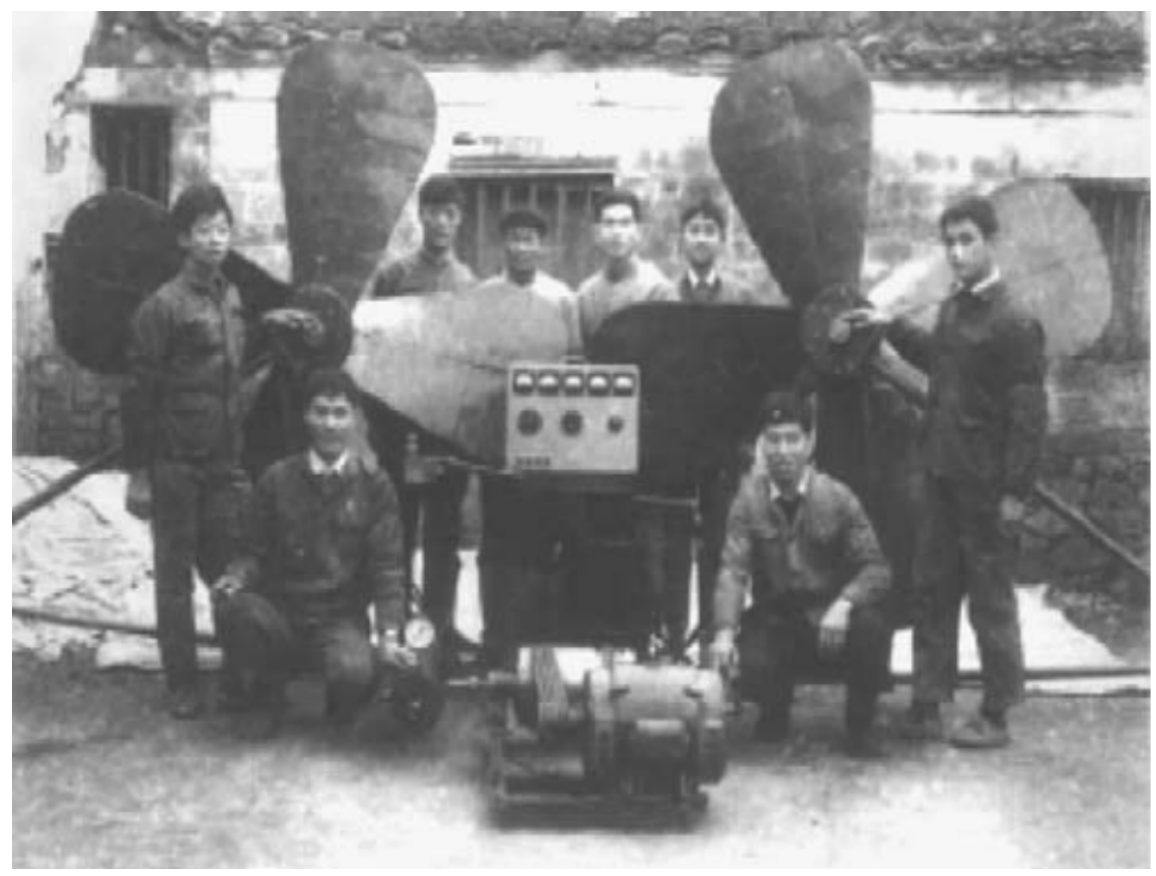

Figure 2. The first tidal current turbine in China in 1970s. Reproduced from [6], Elsevier.

\subsection{HEU}

HEU has been one of the earliest institutes to study TCPGS in China. A total of $60 \mathrm{~W}$ and 1 kW TCPGSs were successfully developed in 1984 and 1989, respectively. From 1996 to 2005, HEU successfully and independently developed power generation devices that had different forms of energy acquisition, such as vertical-axis and horizontal-axis, and floating and stationary carriers, mainly including: "Wanxiang I", "Wanxiang II", "Haiming I", "Haineng I", "Haineng II" and "Haineng III", etc. [4].

Sponsored by the Ministry of Science and Technology (MOST), "Wanxiang I" (70 kW) became the first experimental floating TCPGS in China (see in Figure 3). This experimental demonstration power station adopts a floating double-rotor vertical-axis turbine [18]. Each rotor, which is $2.2 \mathrm{~m}$ in diameter, consists of four variable-pitch blades. The chord length and height of the blade are $0.65 \mathrm{~m}$ and $2.5 \mathrm{~m}$, respectively. The generator, hydraulic speed increasing mechanism, and control equipment are placed in a ship-shaped carrier, such as a catamaran (18 $\mathrm{m}$ long and $9 \mathrm{~m}$ wide), which is fixed by an anchor system consisting of sets of heavy blocks, anchor chain, and buoy [4,9]. The experiment of this power station was carried out in April 2002 in Guishan Channel in Daishan, Zhejiang Province. It generated a peak power of $25 \mathrm{~kW}$ when the flow velocity was $2.5 \mathrm{~m} / \mathrm{s}$ [19]. "Wanxiang I" was built at the same time as the Kobold power station in Italy [20], and was also the first experimental floating TCPGS in the word.

"Wanxiang II" (40 kW), supported by MOST, is the first submarine vertical-axis TCPGS in China (see in Figure 4). The demonstration power station adopts a birotor vertical-axis variable-pitch turbine [4]. The special carrier (size: $7.6 \mathrm{~m} \times 7.6 \mathrm{~m} \times 5.0 \mathrm{~m}$, weight: $61.7 \mathrm{~T}$ ) is composed of an engine room, a double-ducted structure (Venturi effect) which can enhance flow velocity, a turbine, a pontoon, caisson, and legs. The mechanical acceleration system and generator are sealed in the engine room $[9,16]$. It is easy to install and maintain with the functions of diving and floating. In December 2005, it was tested and run in the Xiaomentou Channel in Daishan, Zhejiang Province [18]. 


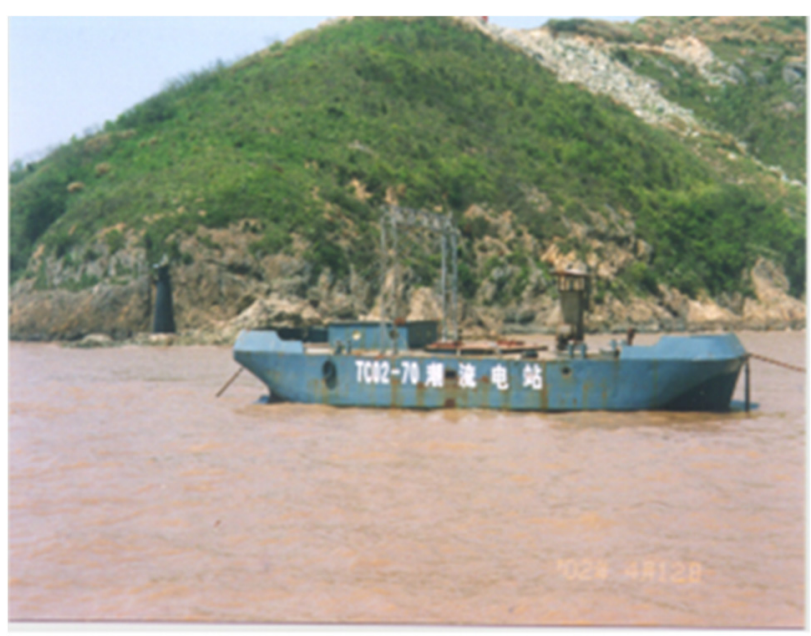

Figure 3. “Wanxiang I"—experimental floating TCPGS. Reproduced from [21], Elsevier.
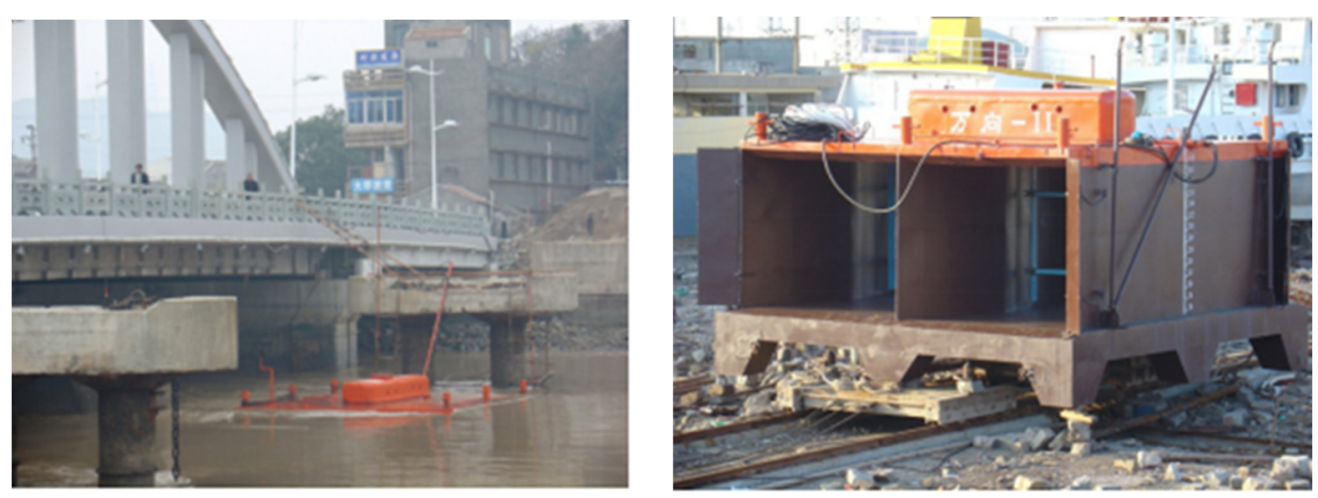

Figure 4. "Wanxiang II"- the first submarine vertical-axis TCPGS. Reproduced from [21], Elsevier.

"Haiming I" $(10 \mathrm{~kW})$ is the first submarine vertical-axis TCPGS for long-term demonstration operation in China (see in Figure 5). The power station (size: $9.0 \mathrm{~m} \times 7.5 \mathrm{~m} \times 6.5 \mathrm{~m}$, weight: $20 \mathrm{~T}$ ) adopts a horizontal-axis fixed-pitch turbine, an efficient expansion-type deflector and a direct-drive permanent magnet synchronous generator (PMSG). This device is supported by a three-legged base frame that can be lifted for maintenance [14,16,22]. It has a $180^{\circ}$ self-adaptive reversing mechanism, which enables the turbine to adapt to the bidirectional current [23]. Its rated output power is $10 \mathrm{~kW}$, and it has $2 \mathrm{~m} / \mathrm{s}$ of rated water velocity. In order to achieve the same output power, the water velocity would need to reach $2.3 \mathrm{~m} / \mathrm{s}$ if there was no deflector. The efficiency of "Haiming I" is tested to be about $35 \%$ [4,9,22].

This power station generates $400 \mathrm{~V} / 50 \mathrm{~Hz}$ three-phase electricity and has some basic features, such as overcurrent protection, overvoltage protection, and undervoltage protection [16]. It can realize automatic variable-speed operation. At the end of September 2011, it was put into operation in Xiaomentou Channel in Daishan, Zhejiang Province [24]. During the six-month trial, the accumulative power generation reached 12,000 kWh and the system efficiency reached $34.5 \%$ [22,25]. This indicated that China had made a landmark breakthrough in the research field of horizontal-axis TCPGS and reached the world's most advanced level in terms of hydrodynamics and its performance.

This project was supported by the State Oceanic Administration (SOA), namely the current Ministry of Natural Resources (MNR). It was jointly completed by SOA, HEU, Harbin Institute of Large Electrical Machinery, Daishan Gaoting shipyard, the Science and Technology Bureau, the Ocean Bureau of Daishan, and other local government departments. 
It was an achievement of collaborative research by the government, universities, scientific research institutes and enterprises.

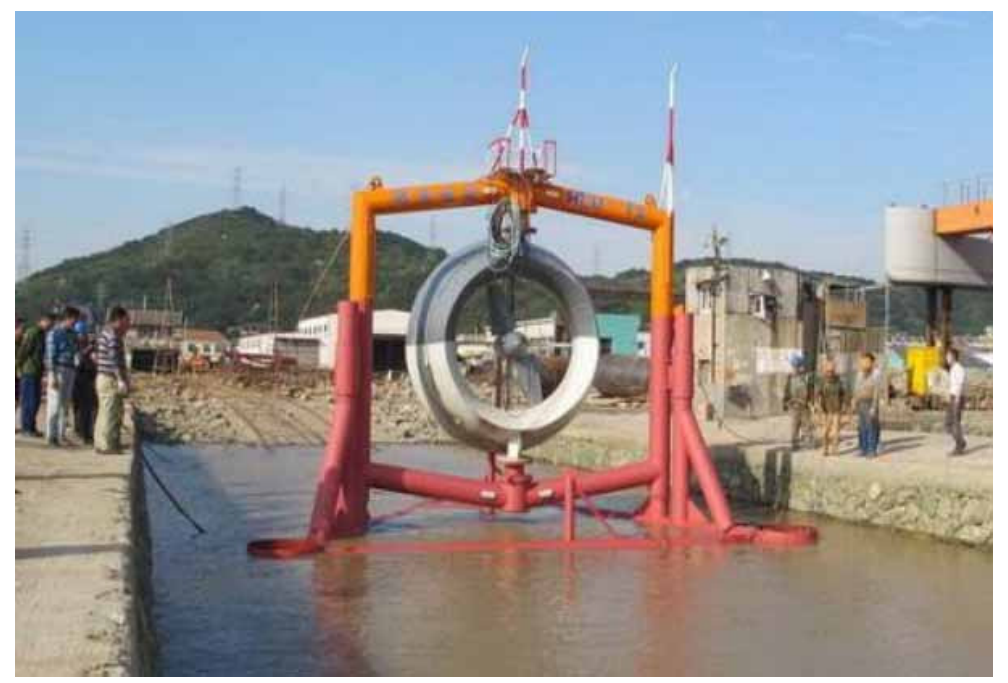

Figure 5. "Haiming I"-10kW submarine vertical-axis TCPGS. Reproduced from [4].

Funded by MOST, "Haineng I" $(2 \times 150 \mathrm{~kW})$, is the first 100-kilowatt-level offshore floating vertical-axis demonstration TCPGS in China (see in Figure 6). For this TCPGS, two $150 \mathrm{~kW}$ generators and control equipment are equipped in a floating catamaran (size: $24 \mathrm{~m} \times 13.9 \mathrm{~m} \times 2.0 \mathrm{~m}$ ) fixed by four sets of anchors [9,25]. It adopts two vertical-axis turbines that are $4 \mathrm{~m}$ in diameter, including a 4-blade variable-pitch turbine and a 2-layer 2-blade fixed-pitch cross turbine with $1.8 \mathrm{~m} / \mathrm{s}$ of cut-in speed and $2.5 \mathrm{~m} / \mathrm{s}$ of cut-out speed. In August 2012, it was tested and ran in Guishan Channel in Daishan, Zhejiang Province [4,14]. The measured system efficiency was over 30\% [9]. It marked a solid step forward for China's TCPGS technology towards industrialization.
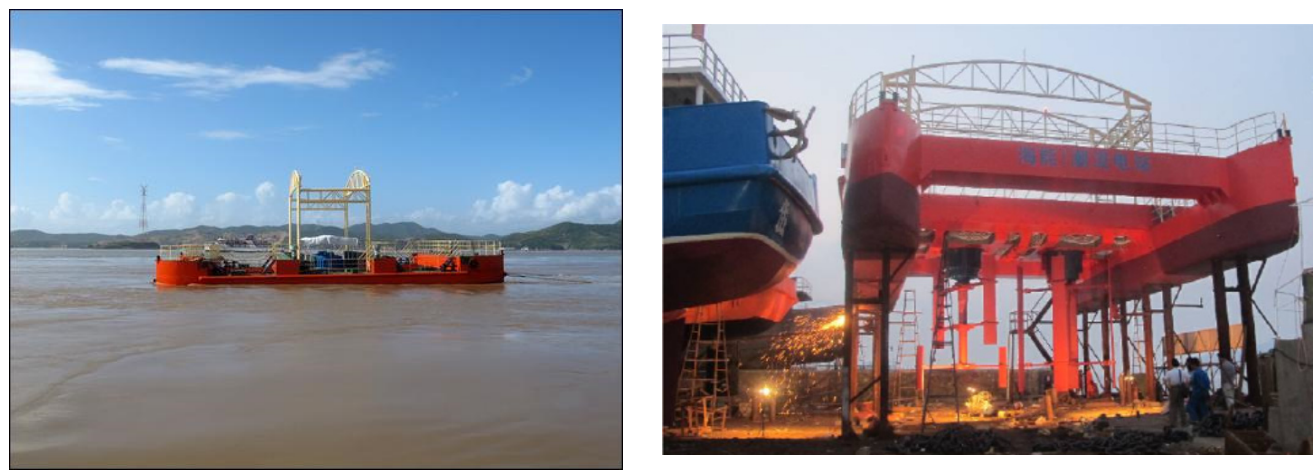

Figure 6. "Haineng I" $-2 \times 150 \mathrm{~kW}$ floating vertical-axis demonstration TCPGS. Reproduced from $[22,26]$.

"Haineng II" $(2 \times 100 \mathrm{~kW})$, also called Zhaitang Island Isolated Hybrid Power Demonstration Station, consists of a cruciform carrier, two columns and four groups of high-elastic mooring systems (see in Figure 7). A total of two columns are, respectively, equipped with a horizontal-axis variable-pitch turbine with a diameter of $12 \mathrm{~m}$. The turbine directly connects the low-speed PMSG with a power of $100 \mathrm{~kW}$ and can adapt to bidirectional tidal current. The rated flow velocity is $1.7 \mathrm{~m} / \mathrm{s}$ with $0.6 \mathrm{~m} / \mathrm{s}$ of cut-in speed and $2 \mathrm{~m} / \mathrm{s}$ of cut-out speed $[4,5,14,27]$. In June 2013, it was installed near Zhaitang Island, Shandong Province, becoming an important part of the " $500 \mathrm{~kW}$ marine energy independent power system demonstration project", which was sponsored by SFPMRE of SOA and implemented by 
China National Offshore Oil Corporation [22]. This project consisted of $150 \mathrm{~kW}$ wind turbine, $50 \mathrm{~kW}$ PV system, $2 \times 100 \mathrm{~kW}$ floating TCPGS (HEU) and $2 \times 50 \mathrm{~kW}$ fixed TCPGS (OUC) [25].
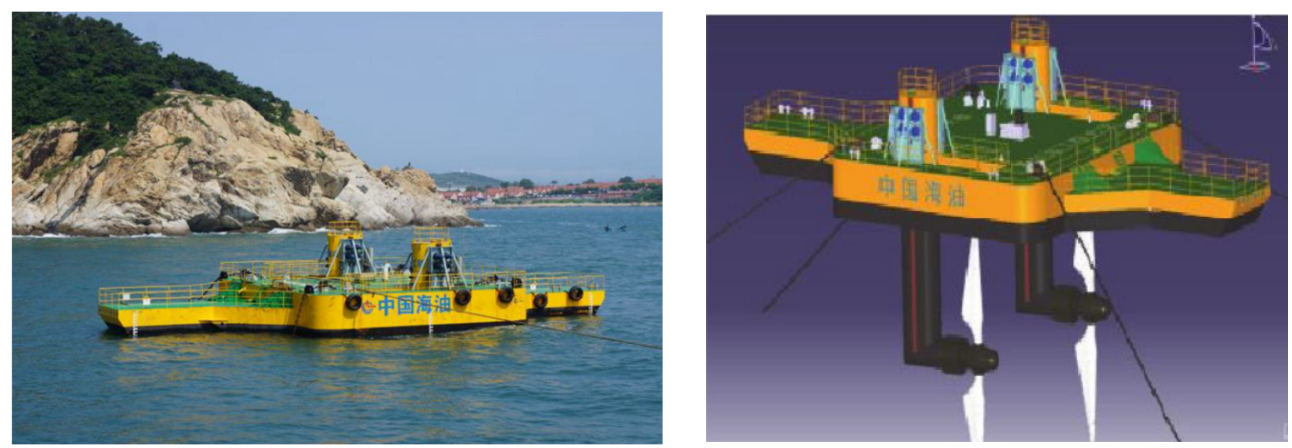

Figure 7. "Haineng II"-2 × $100 \mathrm{~kW}$ floating horizontal-axis TCPGS. Reproduced from [28,29].

"Haineng III" $(2 \times 300 \mathrm{~kW})$ is the largest floating vertical-axis demonstration TCPGS in China (see in Figure 8). This floating demonstration station, also called Daishan Tidal Current Technology Demonstration Station, is equipped with two $300 \mathrm{~kW}$ generators (rated speed: $350 \mathrm{rpm}$ ) on the catamaran, and fixed at the bottom of the sea by four high-elastic mooring systems. It adopts a vertical-axis 2-layer 2-blade cross turbine with a diameter of $6 \mathrm{~m}$, which increases the power generation by twice as much as "Haineng I" [27]. The rated water velocity is $3 \mathrm{~m} / \mathrm{s}$ and the maximum is $3.5 \mathrm{~m} / \mathrm{s}[4,5]$. The cut-in and cut-out speeds are $1.2 \mathrm{~m} / \mathrm{s}$ and $3.5 \mathrm{~m} / \mathrm{s}$, respectively. In December 2013, this station was tested in the Guishan Channel, Daishan, Zhejiang Province. The accumulated power generation time was more than 20 months, and the total efficiency was nearly 30\% [30]. As "Haineng II", this project was also supported by SFPMRE. The completion of this power station marked another solid step towards the industrial development of TCPGS technology in China.

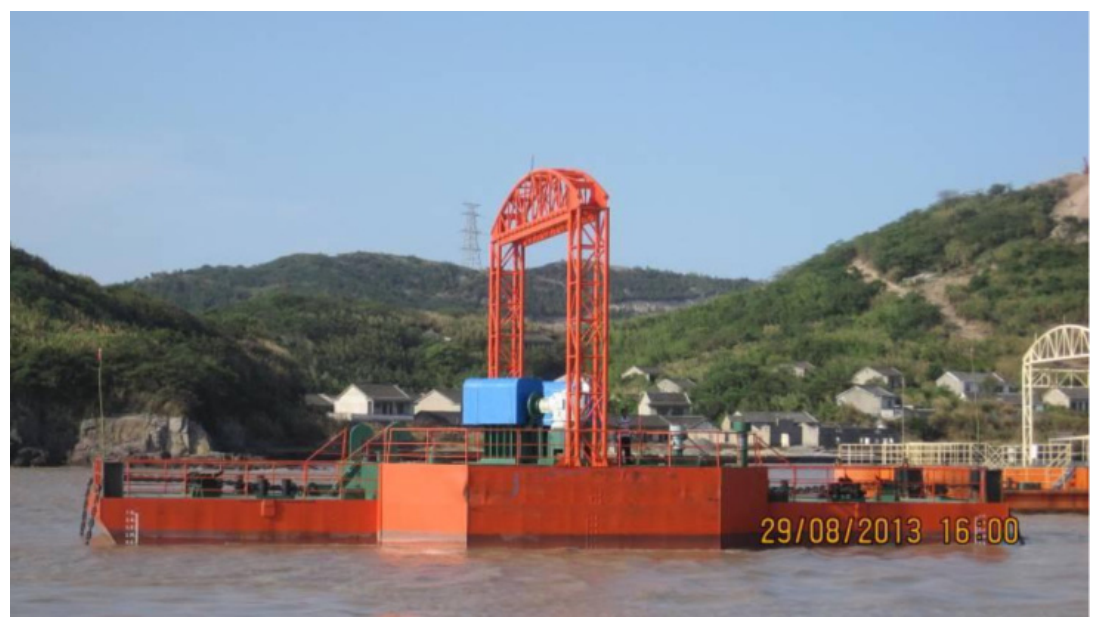

Figure 8. "Haineng II"-2 × $300 \mathrm{~kW}$ floating vertical-axis TCPGS. Reproduced from [22].

\subsection{NENU}

NENU has entered into the field of ocean energy development since 2001. Since then, it has made breakthroughs in many key technologies of TCPGS, such as the sealing technology of generator and the commutation technology of power generation system. With the support of MOST, NENU has made a technological breakthrough in the field of horizontal-axis direct-drive low-speed TCPGS [19].

From November 2006 to December 2008, with the support of MOST, NENU completed the project "Energy Supply Technology for Marine Underwater Instruments" and suc- 
cessfully developed a small $1 \mathrm{~kW}$ floating horizontal-axis low-speed direct-drive TCPGS. This device consists of a horizontal-axis turbine, flexible shaft, generator, and underwater mooring system [31]. In order to start at a low-flow velocity, the turbine adopts eight fixed-pitch blades and connects them with the generator fixed on the fishing boat through the soft shaft (see in Figure 9). The fixed-pitch turbine could solve the problem of the start-up of TCPGS at low-water velocity and the low efficiency in the reversed flow [32].

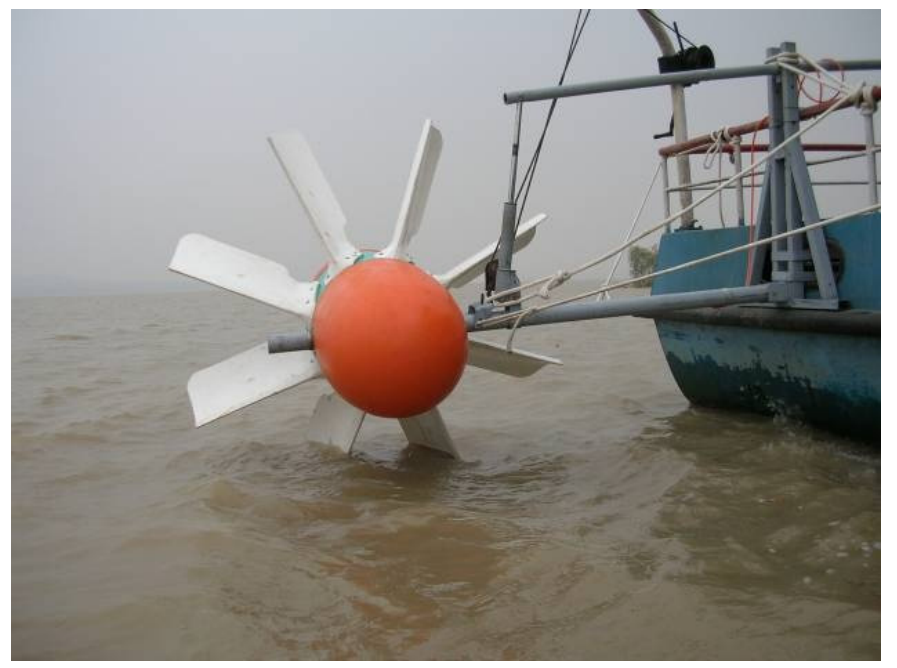

Figure 9. A $1 \mathrm{~kW}$ floating horizontal-axis low-speed direct-drive TCPGS. Reproduced from [33].

In 2009, NENU successfully developed a $2 \mathrm{~kW}$ surface low-speed direct-driven TCPGS funded by MOST (see in Figure 10). The device adopts a 4-blade turbine with an attack angle of $12^{\circ}$. This technique can avoid disasters of floating and sinking, and can also be used for daily maintenance. The test of the device was carried out in the sea near Qingdao, Shandong Province. The system started generating electricity at the water velocity of $0.3 \mathrm{~m} / \mathrm{s}$. When the water velocity is between $0.9 \mathrm{~m} / \mathrm{s}$ and $1 \mathrm{~m} / \mathrm{s}$, the generator can obtain the highest efficiency, and the total efficiency of TCPGS can exceed 30\% [34].

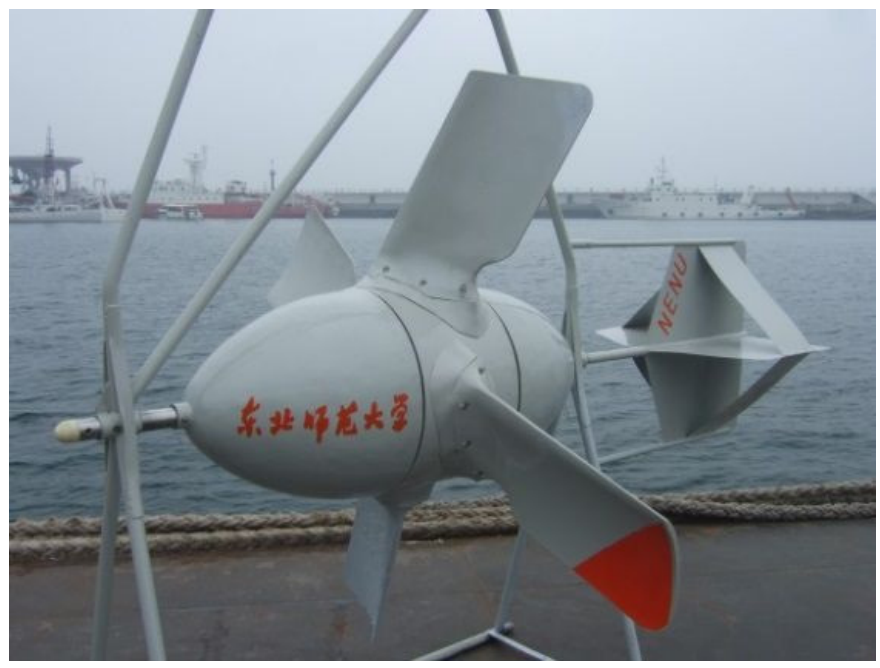

Figure 10. A $2 \mathrm{~kW}$ surface low-speed direct-driven TCPGS. Reproduced from [26].

In 2010, NENU began the research on "Key technologies of $5 \mathrm{~kW}$ modular tidal current energy power supply for ocean observation platform" of SFPMRE (see in Figure 11). This device is equipped with two sets of generators, each with a single capacity of $2.5 \mathrm{~kW}$. Each set, which is fixed by a tower, adopts a 4-blade fixed-pitch lightweight turbine, is $2.6 \mathrm{~m}$ in 
diameter, and has a low-speed direct-drive PMSG sealed underwater. The experimental results showed that the device achieved an average output power of about $2.5 \mathrm{~kW}$ at the rated flow velocity of $2.2 \mathrm{~m} / \mathrm{s}$. It was launched on 4 November 2014 in Zhaitang Island Channel, Shandong Province and operated underwater for 12 months. A single module can meet the power supply of the oceanic buoy and other observation instruments, and has the advantages of a low starting velocity and adaptive flow direction [2].
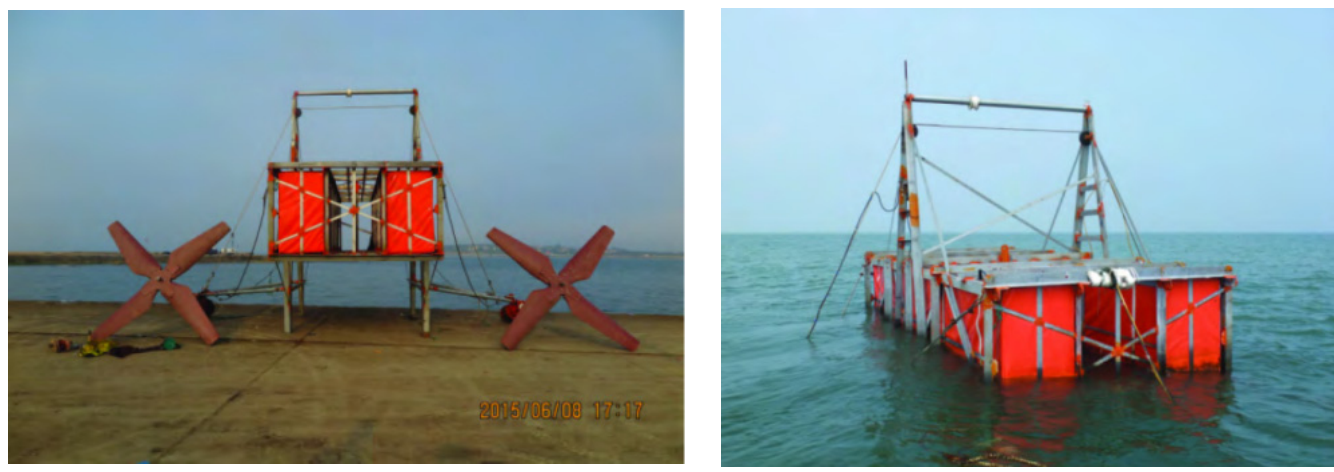

Figure 11. A $5 \mathrm{~kW}$ power supply device for offshore instrument. Reproduced from [1].

In 2011, NENU began a project of " $15 \mathrm{~kW}$ common horizontal-axis self-variable-pitch TCPGS" (see in Figure 12), sponsored by SFPMRE. Based on the optimizing design, the turbine can automatically change the pitch angle by the hydrodynamic force of the blade, which greatly improved the reliability and the utilization coefficient of the turbine. The device was tested in Zhaitang Island Channel, Shandong Province in May 2016. The power generation efficiency was $28.6 \%$ at the flow velocity of $0.7 \mathrm{~m} / \mathrm{s}$, and higher at the rated velocity of $2 \mathrm{~m} / \mathrm{s}$ [35]. This project explored the new technology of a two-direction self-variable-pitch TCPGS, which had strong environmental adaptability and operation reliability. It was very suitable in the sea area of China, due to the short-time high tidal current speed and low average speed.
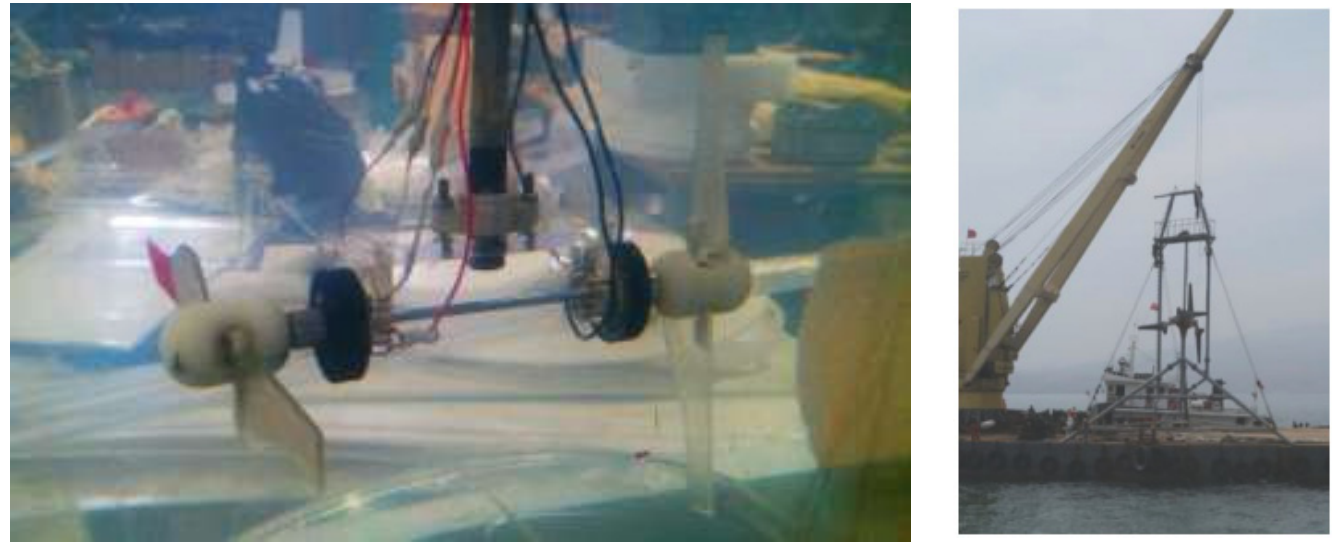

Figure 12. The model and prototype of $15 \mathrm{~kW}$ common horizontal-axis self-variable-pitch TCPGS. Reproduced from [17,35].

In 2013, with the support of MOST, NENU successfully developed a $20 \mathrm{~kW}$ horizontalaxis TCPGS (see in Figure 13). The device weighs $28 \mathrm{~T}$, adopts an asymmetrical 4-blade fixed-pitch turbine that is $5 \mathrm{~m}$ in diameter, and is supported by a tower with four legs. It can automatically change the pitch angles of the blades and has a 180 degree steering mechanism and adaptive reversing tail. Therefore, the turbine can run in both directions of the water. In April 2013, the test operation was completed in Zhaitang Island Channel, Shandong Province. The starting water velocity was $0.7 \mathrm{~m} / \mathrm{s}$, the design water velocity 
was $2.1 \mathrm{~m} / \mathrm{s}$, and the conversion efficiency of the whole system reached $26 \%$. It is the first gravity-based tower-type horizontal axial TCPGS in China $[4,5,14,23]$.

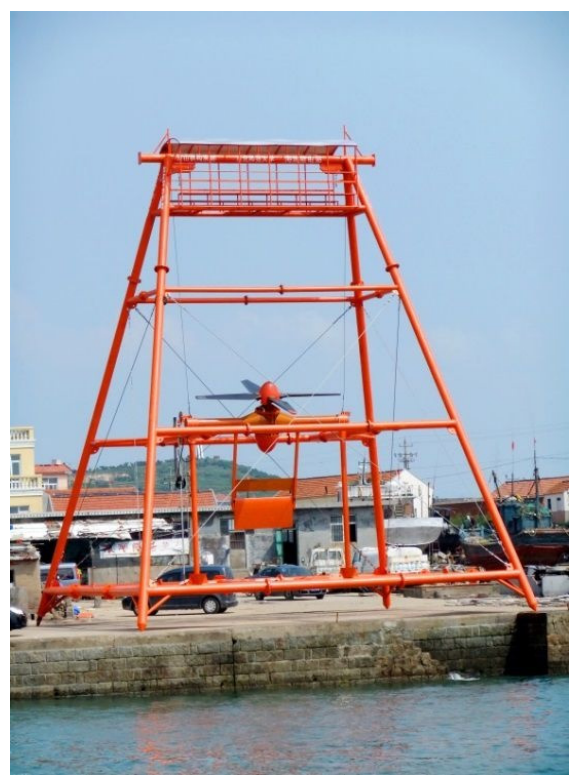

Figure 13. A $20 \mathrm{~kW}$ gravity-based tower-type horizontal-axis TCPGS. Reproduced from [33].

In 2013, NENU and HangZhou JiangHe Hydro-Electric Science \& Technology Co., Ltd. jointly started research and development of a $300 \mathrm{~kW}$ horizontal-axis self-variable-pitch TCPGS with a $690 \mathrm{~V}$ rated voltage, which was supported by SFPMRE (see in Figure 14). The prototype realized the technology of bidirectional self-variable-pitch without power for the first time and tested dynamic sealing. The diameter of the turbine was $16.5 \mathrm{~m}$ and had a $14 \mathrm{rpm}$ rated rotation speed. The rated flow speed was $2 \mathrm{~m} / \mathrm{s}$ and the system could operate at $0.691 \mathrm{~m} / \mathrm{s}$ [36]. The device was launched in Zhoushan, Zhejiang Province on 30 May 2019 and successfully connected to the State Grid. The total conversion efficiency was more than $36 \%$. It was the first TCPGS in the world to realize passive self-variable-pitch and capture bidirectional tidal current energy with high efficiency. It was also the largest horizontal axial TCPGS adopting one direct-drive external rotor generator in Asia [37].
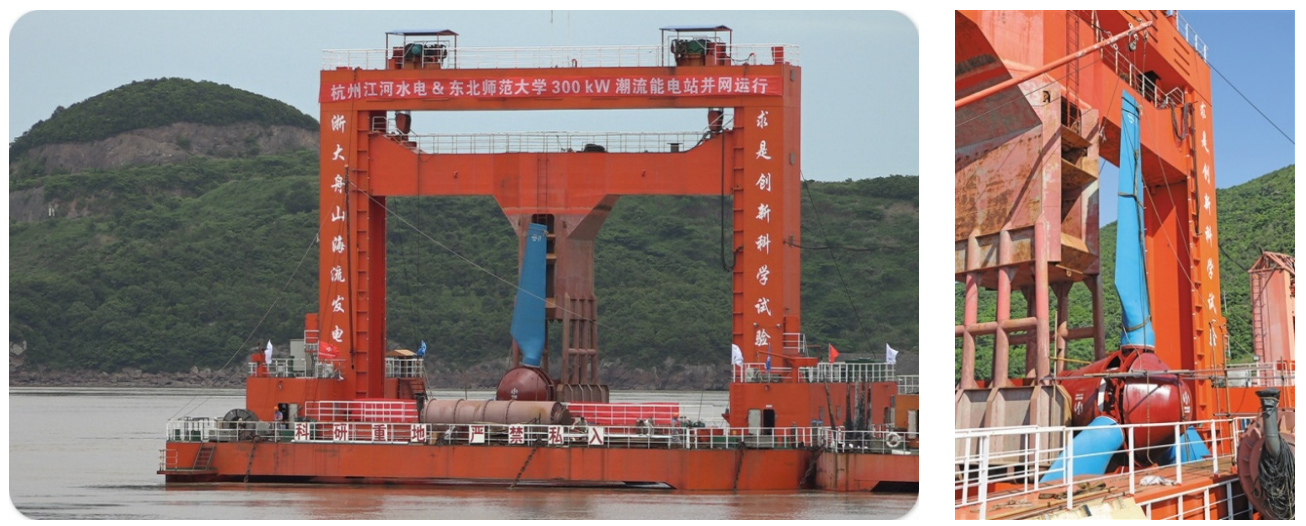

Figure 14. A 300 kW horizontal-axis self-variable-pitch TPCGS. Reproduced from [36,38].

In 2016, these two institutions also participated in the other project of "Demonstration application of power supply system for ocean energy underwater instruments" of China State Shipbuilding Co., Ltd. (Beijing, China), sponsored by SFPMRE. This device adopted the passive self-variable-pitch and moving-free sealing technologies (see in Figure 15). The basic rated parameters mainly included the turbine diameter of $1.8 \mathrm{~m}$, the rated power of 
$120 \mathrm{~W}$, the rated voltage of $36 \mathrm{~V}$, and the rated rotation speed of $28 \mathrm{rpm}$. The system was tested in Qingdao at the end of 2019. According to the results, it could be started at $0.3 \mathrm{~m} / \mathrm{s}$. This device was equipped with rectifier, voltage stabilizer, and energy storage devices, etc. It could continuously supply power to the $300 \mathrm{~m}$ underwater device, especially for ocean observation and monitoring equipment, with a design life of 5 years $[39,40]$.
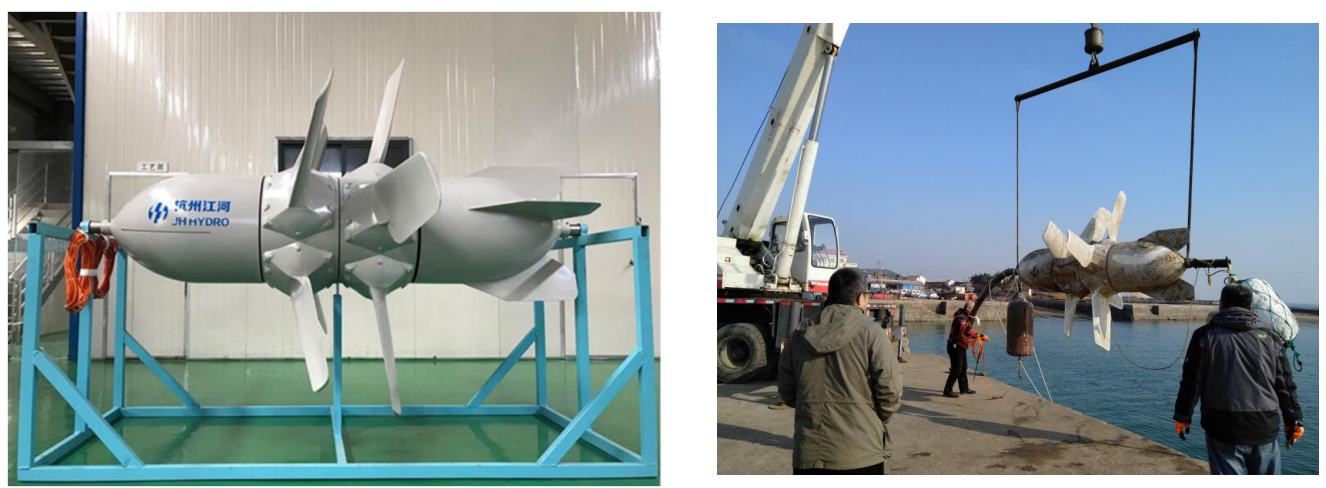

Figure 15. The power supply device for underwater marine instruments. Reproduced from $[40,41]$.

\subsection{ZJU}

Since 2004, ZJU has been committed to the development and utilization of marine current energy. So far, it has successfully developed two series of equipment products: $5 \mathrm{~kW}-650 \mathrm{~kW}$ semi-direct-drive TCPGS series and $50 \mathrm{~W}-75 \mathrm{~kW}$ direct-drive TCPGS series for marine special instruments. ZJU provided the independent and stable electric energy of TCPGS for the isolated island, which could effectively solve the problem of offshore power supply. Moreover, it also took the lead in forming a horizontal-axis TCPGS array grid-connected operation system in China.

In 2006, ZJU developed the first prototype of an "Underwater Windmill" of $5 \mathrm{~kW}$ horizontal-axis fixed-pitch TCPGS at kilowatt level in China (see in Figure 16). The prototype is mainly composed of 3-blade, transmission mechanism, brake, generator (PMSG, $750 \mathrm{rpm}, 5 \mathrm{~kW}$ ), converter, sealing engine room, tower, and other components, and is fixed under water with self-weight. The prototype can make the turbine always face the direction of the water flow by adjusting the water-guide mechanism. The turbine has a diameter of $2.6 \mathrm{~m}$ with a rated speed of $50 \mathrm{rpm}[32,42,43]$. The test was carried out in Xiaomentou Channel, Zhoushan, Zhejiang Province on April 26, 2006. When the flow velocity was around $1.7 \mathrm{~m} / \mathrm{s}$, the generation power could reach $2 \mathrm{~kW}[5,44-46]$.
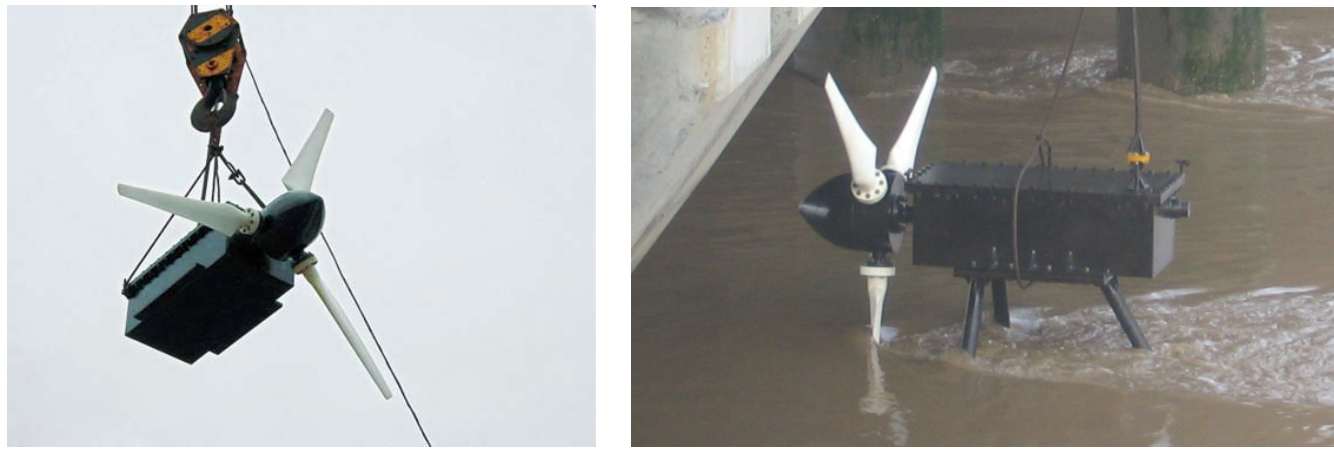

Figure 16. "Underwater Windmill" $-5 \mathrm{~kW}$ horizontal-axis fixed pitch prototype. Reproduced from $[5,45]$.

Since 2007, on the basis of the first horizontal-axis prototype, the research group of ZJU has carried out research on the following two power generation devices simultaneously [46]. 
The $20 \mathrm{~kW}$ horizontal-axis hydraulic variable-speed variable-pitch TCPGS adopts the structure form of the variable pump and variable motor, which can make the pitch angle vary between 0 and $190^{\circ}$ (see in Figure 17) [47]. By changing the displacement of the pump, the maximum energy capture of the system can be realized. The device was debugged and tested in May 2010. According to the relative test results, the hydraulic transmission system can effectively improve the power stability of TCPGS. The system efficiency can be improved by lengthening the blades and through variable-speed operation. This prototype thoroughly verifies the feasibility of the hydraulic variable-pitch mechanism for small and medium-sized TCPGS [48].
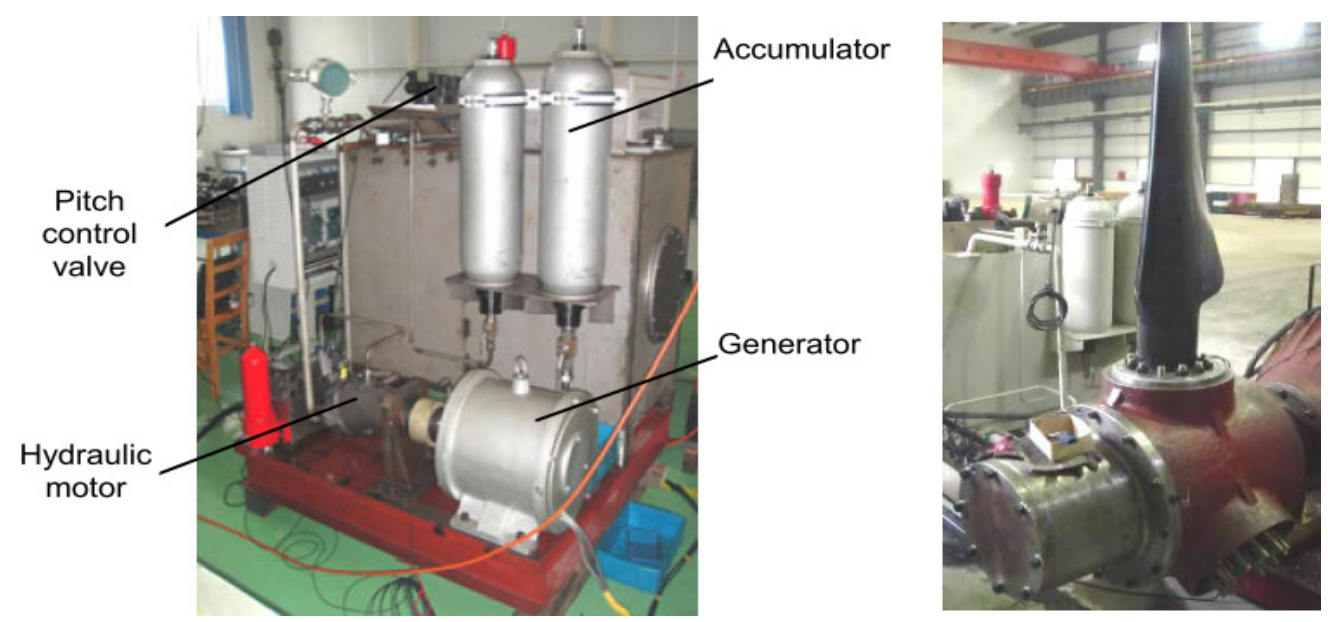

Figure 17. The $20 \mathrm{~kW}$ horizontal-axis hydraulic variable-speed variable-pitch TCPGS. Reproduced from [49].

The $25 \mathrm{~kW}$ horizontal-axis semi-direct-drive TCPGS has a $4.4 \mathrm{~m}$ turbine diameter, $0.44 \mathrm{~m}$ turbine hub, $45 \mathrm{rpm}$ rated speed, and $2 \mathrm{~m} / \mathrm{s}$ in the design rated flow velocity (see in Figure 18). The turbine adopts NACAA 63-4 series of blades. The optimal tip speed ratio is 5.1, and the relative maximum power point coefficient is 0.354 [5,50,51]. On 10 May 2009, the device was conducted on a 7-day trial in Daishangang Channel, Zhejiang Province. It started to generate at around $1.3 \mathrm{~m} / \mathrm{s}$ and obtained the peak power of $29.1 \mathrm{~kW}$, and 0.341 as the maximum power factor $[7,52]$.

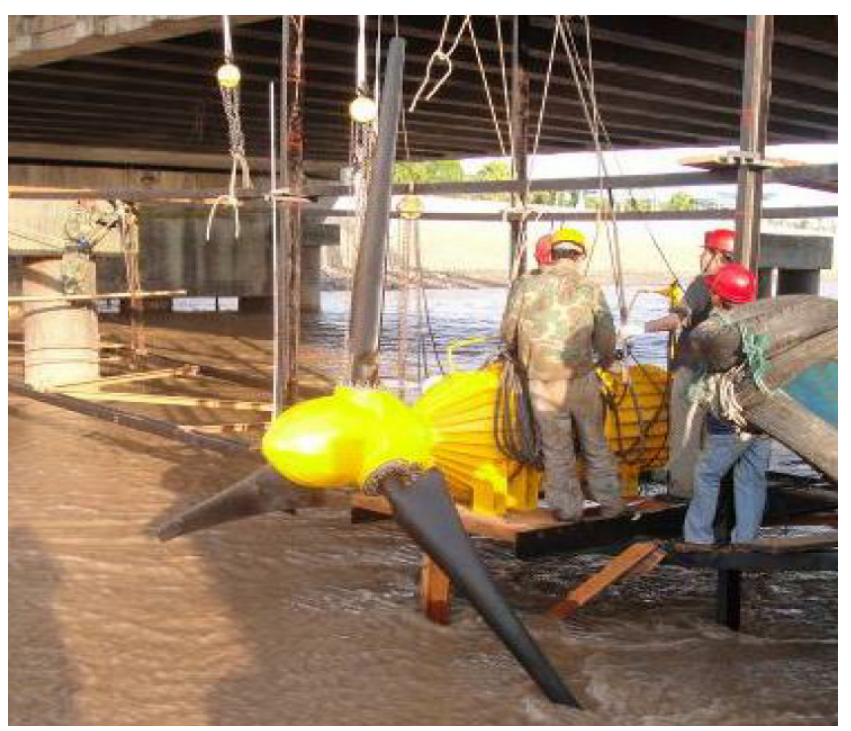

Figure 18. The $25 \mathrm{~kW}$ horizontal-axis semi-direct-drive TCPGS. Reproduced from [21], Elsevier. 
In 2013, ZJU started to develop a "60 kW semi-direct-drive horizontal-axis TCPGS with large length-diameter ratio" independently of SFPMRE (see in Figure 19). PMSG with $180 \mathrm{rpm}$ and six pole pairs is selected by this device. The turbine adopts NACAA 63-4 series blades that are around $7 \mathrm{~m}$ in diameter [53,54]. Its rated speed is $30 \mathrm{rpm}$, and it has a 6.1 optimal tip speed ratio. The designed rate and maximum current speeds are $2 \mathrm{~m} / \mathrm{s}$ and $3.5 \mathrm{~m} / \mathrm{s}$, respectively. The device was tested on the floating test platform of Zhairuoshan Ocean Science and Technology Demonstration Island in Zhejiang Province on May 8, 2014. The system began to start up at $0.6 \sim 0.8 \mathrm{~m} / \mathrm{s}$ and could generate nearly $60 \mathrm{~kW}$ under rated working conditions. The power coefficient was up to 0.436 , and the total system efficiency was 39\% [24,54]. During the test, the maximum power could reach $118 \mathrm{~kW}$, and the daily output electricity was 100 300 kWh per day. At that time, it became the best TCPGS, and had the largest average daily generation power, the longest actual generation time, and the maximum accumulative generation capacity (more than $25 \mathrm{MWh}$ ) in China [55]. Since then, this station became Zhairuoshan Tidal Current Energy Power Demonstration Station; the test platform which was supported by MNR and MOST, turned to be ZJU Tidal Current Energy Demonstration Platform to provide installing and testing service for TCPGS developers.
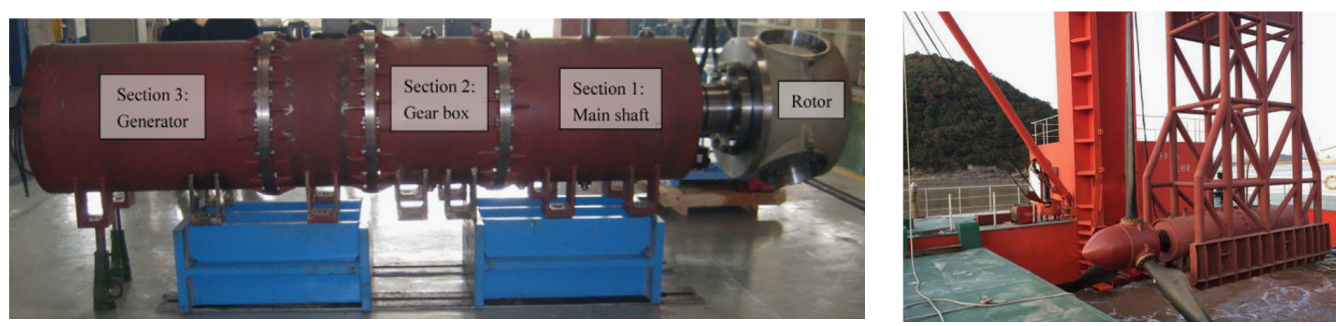

Figure 19. A $60 \mathrm{~kW}$ semi-direct-drive horizontal-axis generator set. Reproduced from [53,56], Elsevier.

In addition, in 2013, ZJU and Guo Dian United Power Co., Ltd. (GDUP) also successfully applied for the project of "Product design and manufacturing of $2 \times 300 \mathrm{~kW}$ TCPGS engineering prototype" of SFPMRE [20,57]. In March 2018, GDUP developed a $300 \mathrm{~kW}$ TCPGS with a $270^{\circ}$ electric pitch control system and underwater video technology relying on National Key Laboratory of Tidal Ocean Power Generation Technology (see in Figure 20). The device adopts a horizontal-axis turbine with two blades, semi-direct-drive transmission mode and mooring system. It can achieve the high energy capture efficiency of forward and backward tidal current flow and the optimal balance between the energy capture and the power generation efficiency. This device has a $7.25 \mathrm{~m}$-long blade, $2 \mathrm{~T}$ total weight and $2.0 \mathrm{~m} / \mathrm{s}$ rated flow velocity.
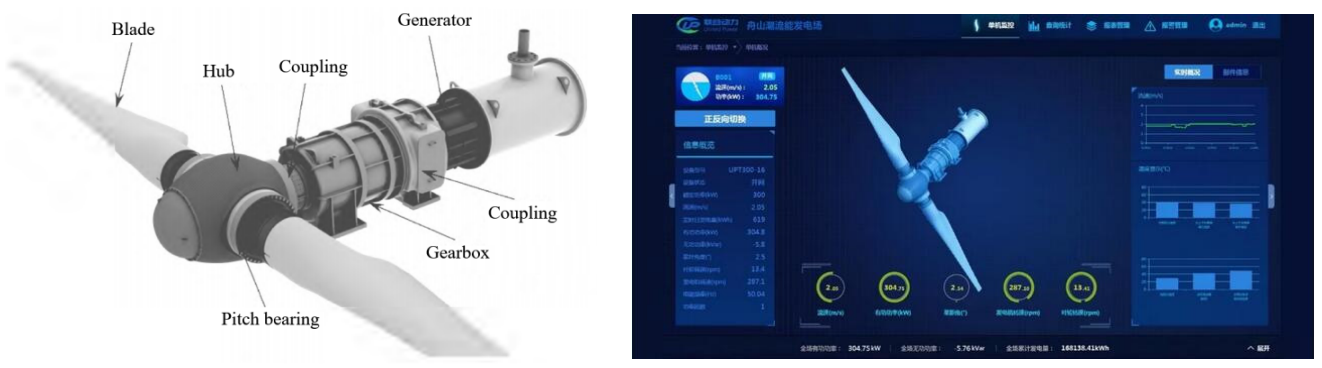

Figure 20. Model of $300 \mathrm{~kW}$ TCPGS. Reproduced from [58,59].

On 31 March 2018, the trial was successfully completed in the sea area of Zhairuoshan Island, Zhejiang Province and the device was connected to the grid smoothly. According to the test, the unit could realize full-power generation at the water velocity of $1.9 \mathrm{~m} / \mathrm{s}$ instead of rated speed of $2 \mathrm{~m} / \mathrm{s}$; the monthly average available hours were $167 \mathrm{~h}$; the equivalent annual average available hours exceeded 2000 h. At the end of November 2018, 
the cumulative power generation was $288 \mathrm{MWh}$ [58]. Significantly, this project has many leading indicators: low cut-in velocity of $0.5 \mathrm{~m} / \mathrm{s}$, small swept area per $\mathrm{kW}$ of $0.82 \mathrm{~m}^{2} / \mathrm{kW}$, light unit weight per $\mathrm{kW}$ of $0.107 \mathrm{~T} / \mathrm{kW}$ and a high total conversion efficiency up to $40 \%$.

From 2015, ZJU began to develop a $120 \mathrm{~kW}$ horizontal-axis semi-direct-drive hydraulic variable-pitch TCPGS under the support of SFPMRE in China (see in Figure 21). The turbine has a diameter of $10 \mathrm{~m}$, and adopts NACA 634xx series blades with the optimal tip speed ratio of six. The hydraulic variable-pitch structure is adopted to realize the forward and reverse action of the blade with the rated pitch rate of $1 \%$ s by the electro-hydraulic proportional directional valve. Consequently, the turbine can realize bidirectional operation with variable-pitch angle of $0 \sim 180^{\circ}$. The designed rated flow velocity is $2 \mathrm{~m} / \mathrm{s}$ and the power coefficient is 0.45 . In May 2016, it was tested in the sea area of Zhairuoshan Island, Zhejiang Province. According to the results, the starting flow velocity was $0.85 \mathrm{~m} / \mathrm{s}$. When the tidal current velocity was more than $2 \mathrm{~m} / \mathrm{s}$, the system output power closed to $120 \mathrm{~kW}$ with the maximum measured power coefficient of 0.37 . This unit has been in trial operation for more than 2 months, and exceeded 13 MWh power generation [57,60].
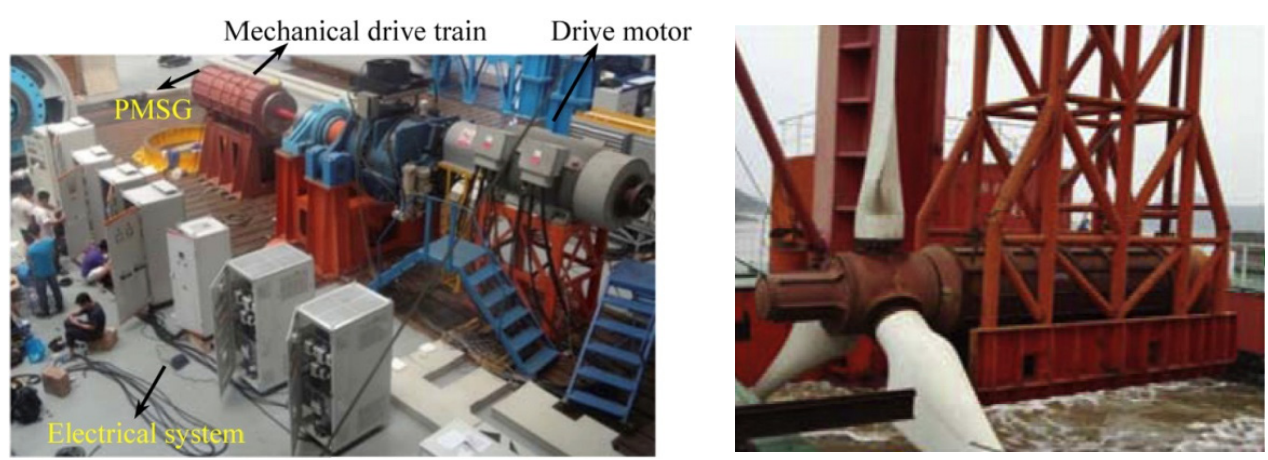

Figure 21. A $120 \mathrm{~kW}$ horizontal-axis semi-direct-drive hydraulic variable-pitch generator set. Reproduced from [60], Elsevier.

In 2017, ZJU started to develop a $650 \mathrm{~kW}$ semi-direct-drive generator set with a large ratio of length to diameter supported by a 4-year SFPMRE project (see in Figure 22) [18]. The device adopts a medium-speed PMSG with a rated speed of $300 \mathrm{rpm}$ and NACA 63-421 series blade with the optimum tip speed ratio of 5.8. The diameters of the turbine and hub are $15.45 \mathrm{~m}$ and $1.75 \mathrm{~m}$, respectively. The rated flow velocity is $2.5 \mathrm{~m} / \mathrm{s}$, and the maximum power coefficient is 0.396 . In the second half of 2017, TCPGS unit was tested in the sea and connected to the grid successfully. The power coefficient was estimated above 0.3848 , which was very close to the theoretical value. According to these sea trail data, the unit was continuously optimized in design and process. In 2020, this improved device was launched and operated again, and reached the maximum power of up to $637 \mathrm{~kW}$. At that time, it had become the largest single capacity of TCPGS in China [61,62].
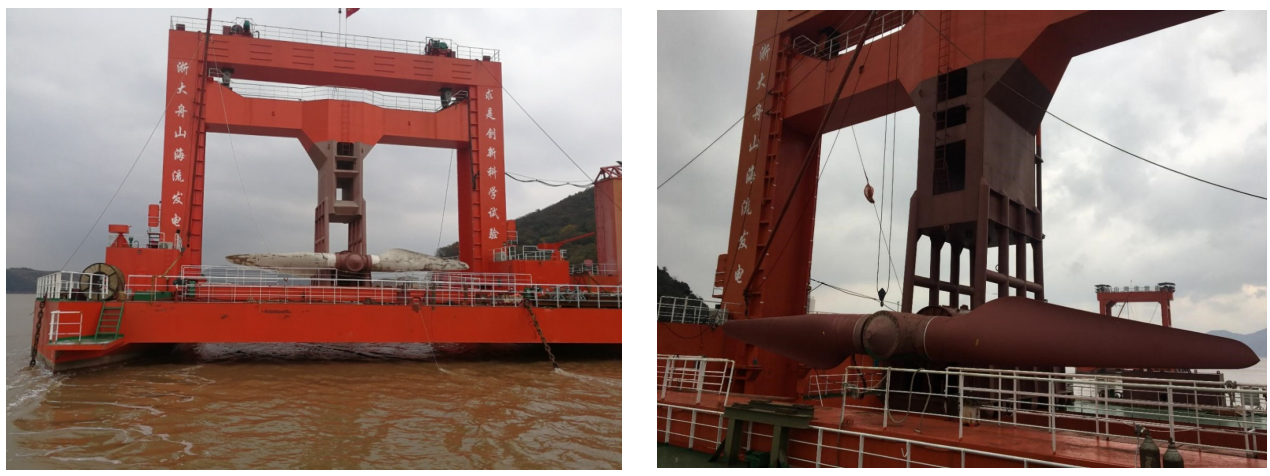

Figure 22. Prototype launched in 2017 (left) and optimized prototype in 2020 (right). Reproduced from [62]. 

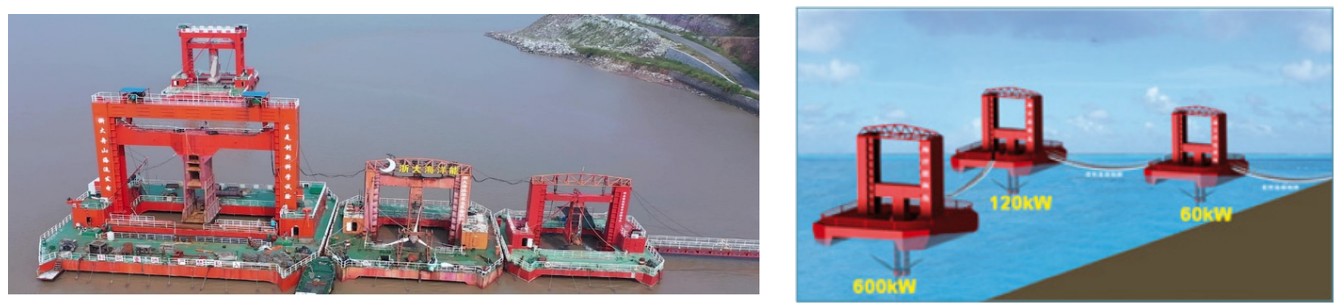

Figure 23. Array operation of multi TCPGS units of ZJU. Reproduced from $[62,63]$.

\subsection{OUC}

OUC started the exploration of TCPGS in 2006, mainly focusing on the research of "flexible blade TCPGS", and developed a unique flexible sail-wing turbine to improve the utilization rate of energy [21,32].

In 2006, OUC commenced to develop a " $5 \mathrm{~kW}$ flexible blade TCPGS" (see in Figure 24). The device adopts a double-floating hull as the carrier. The turbine, that has a triangular flexible blade, can automatically adjust the attack angle with high torque and energy acquisition coefficients to obtain the maximum power. The device can start itself at any corner position, and the starting velocity is low. At the end of 2008, the trial was conducted in Zhaitang Island Channel in Qingdao, Shandong Province. When the water velocity was $1.7 \mathrm{~m} / \mathrm{s}$, the power could reach $3.2 \mathrm{~kW}[5,29,64-66]$.
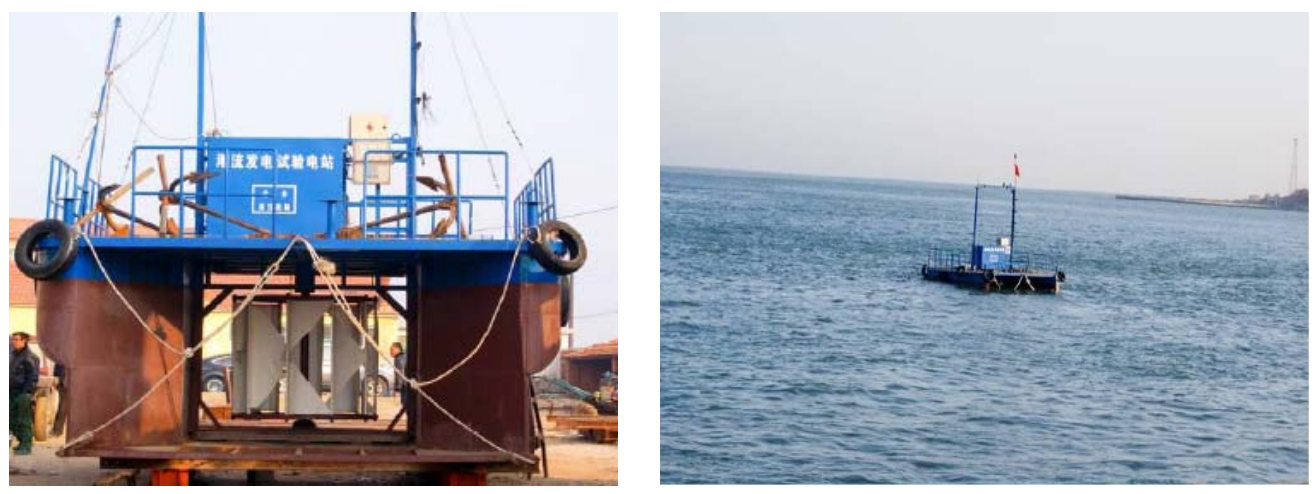

Figure 24. A 5 kW flexible blade TCPGS. Reproduced from [29,67].

In 2010, OUC started the research on the $20 \mathrm{~kW}$ horizontal-axis variable-pitch TCPGS "Haichuan" supported by SFPMRE (see in Figure 25). The device adopts a snorkelling carrier $(14 \mathrm{~m} \times 8 \mathrm{~m} \times 1.5 \mathrm{~m})$ with a gantry lifting mechanism. The turbine adopts NACA 63-8 series blade with a diameter of $4.57 \mathrm{~m}$ [68]. The designed rated flow velocity is $1.7 \mathrm{~m} / \mathrm{s}$. Several techniques are used, such as electric variable-pitch system and maximum power point tracking control, as well as the semi-direct-drive mode which can produce a low starting flow velocity. This device was finally installed and tested in Zhaitang Island Channel of Qingdao, Shandong Province in June 2015. The relative starting flow velocity was verified to be about $0.5 \mathrm{~m} / \mathrm{s}$. The energy capture coefficient of the turbine reached 0.433 with the total efficiency of $35.2 \%$. This device cumulatively operated for more than 16 months $[24,69,70]$.

In 2013, OUC commenced with the project of "100 kW horizontal-axis TCPGS", which was part of the "500 kW marine energy independent power system demonstration project" of SFPMRE (see in Figure 26). This system contains $2 \times 50 \mathrm{~kW}$ units: "Haiyuan-I" and "Haiyuan-II". The size of each device is $18 \mathrm{~m} \times 12 \mathrm{~m} \times 17.5 \mathrm{~m}$. The turbine has a 3-blade structure that is $10.5 \mathrm{~m}$ in diameter, and has $0.9 \mathrm{~m} / \mathrm{s}$ of cut-in speed and $2.5 \mathrm{~m} / \mathrm{s}$ of cut-out speed $[5,14,18]$. The device adopts triangle-shaped support structure, variable-pitch control 
technology and a semi-direct-drive transmission system. The starting flow velocity is $0.9 \mathrm{~m} / \mathrm{s}$, and the rated flow velocity is $1.5 \mathrm{~m} / \mathrm{s}$ [28,31]. In August 2013, the devices began the demonstrated operation near Zhaitang Island, Qingdao, Shandong Province [4,46]. The results showed that the devices operated well with stable output, the starting flow velocity was $0.4 \sim 0.5 \mathrm{~m} / \mathrm{s}$ at the optimal energy acquisition pitch angle, and the efficiency was $36.1 \%$.
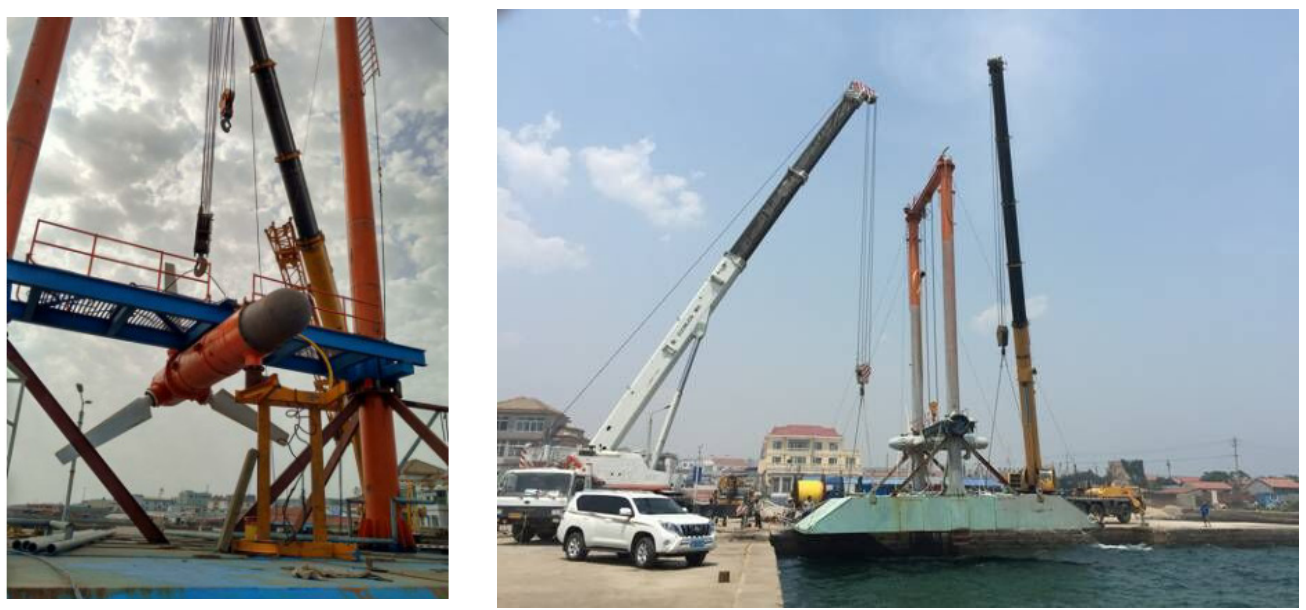

Figure 25. "Haichuan"-20 kW horizontal-axis variable-pitch TCPGS. Reproduced from [70].
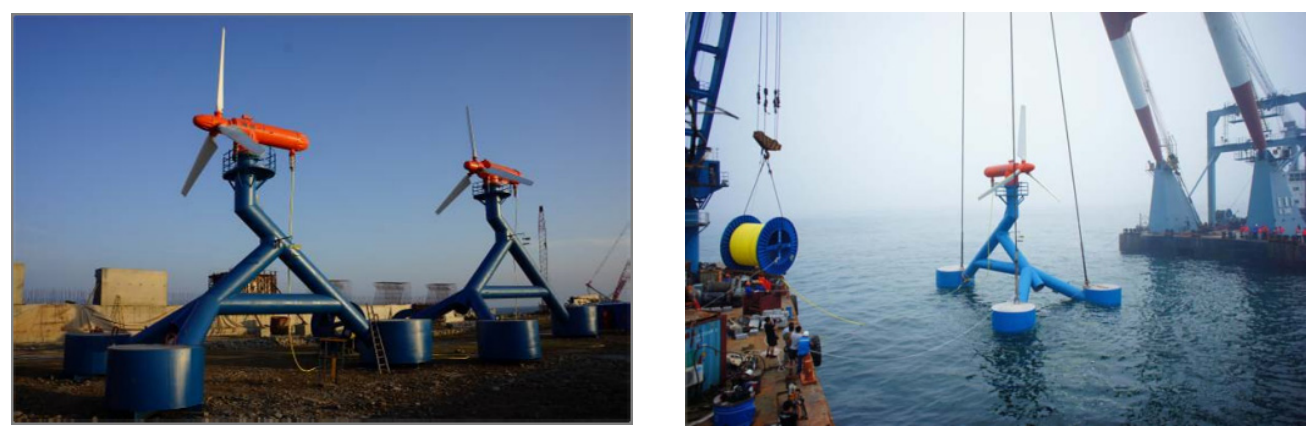

Figure 26. A $100 \mathrm{~kW}$ horizontal-axis TCPGSs. Reproduced from [4,29].

\subsection{DUT}

From August 2011 to August 2013, DUT was sponsored by SFPMRE to carry out "Research and test of a new vertical shaft direct-drive TCPGS". According to this fund, DUT developed a $15 \mathrm{~kW}$ vertical-axis direct-drive TCPGS (see in Figure 27). This device adopts a PMSM with a rated speed of $65 \mathrm{rpm}$ and rated voltage of $380 \mathrm{~V}$. The turbine employs a coaxial three-blade double-rotor structure and has two sets of blades, each with a diameter of $3.8 \mathrm{~m}$ and a span of $2 \mathrm{~m}$. The shift angle between the two sets of blades is $60^{\circ}$, which is used to improve the self-starting performance of the turbine. NACA0018 is adopted for the blade and its chord length is $0.5 \mathrm{~m}$ [71,72]. In October 2013, the sea trial was carried out in the channel between Dachangshan and Xiaochangshan Islands in Liaoning Province. The minimum self-starting flow velocity was $0.6 \mathrm{~m} / \mathrm{s}$. The maximum output power could reach $8 \mathrm{~kW}$ when the flow velocity reached $1.3 \sim 1.4 \mathrm{~m} / \mathrm{s}$ [66]. The measured maximum energy conversion efficiency was about $49 \%$, and the energy harvesting efficiency in open waters could be more than $30 \%$. This device has become the first tidal current energy test power station in the Yellow Sea and Bohai Sea in northern China. 


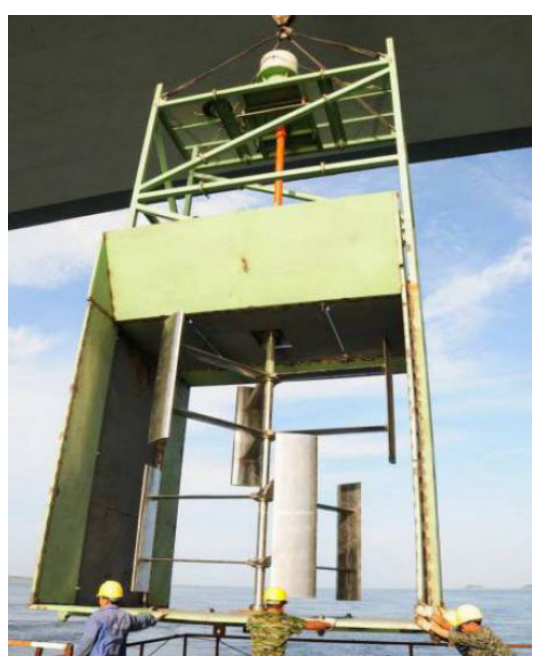

Figure 27. A $15 \mathrm{~kW}$ vertical-axis direct-drive TCPGS. Reproduced from [73].

\section{7. $L H D$}

LHD was founded in April 2013. It is the first high-tech enterprise focusing on the tidal current energy research and development in China. It aims to develop "7.5 MW LHD Modular Large-scale Tidal Current Power Generation Units". This project is implemented in two phases: 3.4 MW "Scientist - Overseas Chinese Federation" of Stage I and 4.1 MW "Entrepreneur · Overseas Returnee" of Stage II (see in Figure 28) [74].
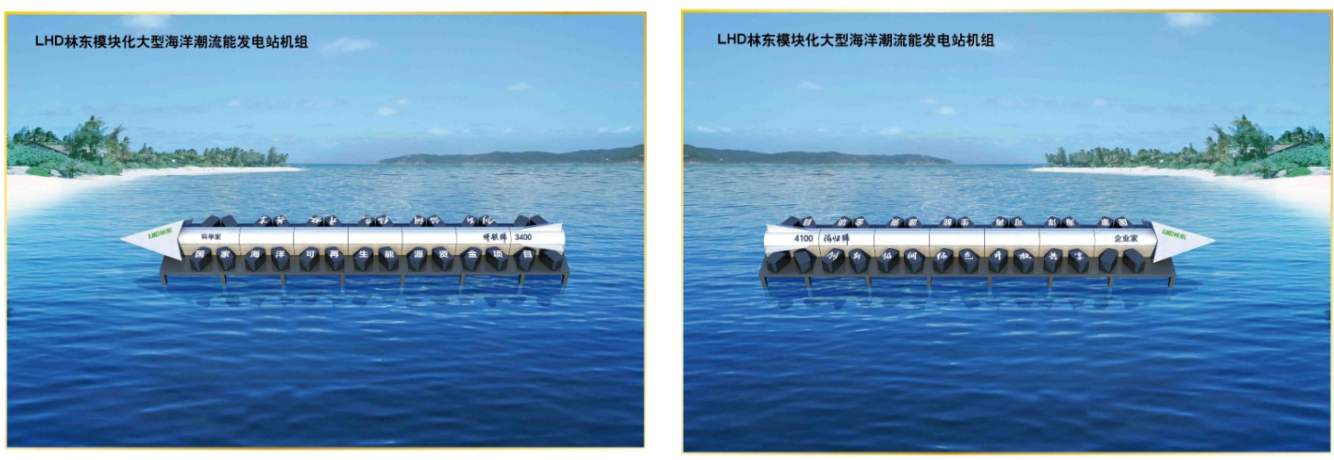

Figure 28. A 3.4 MW "Scientist.Overseas Chinese Federation" (left) and 4.1 MW Entrepreneur Overseas Returnee" (right). Reproduced from [74].

Supported by SFPMRE and Zhejiang Major Science Technology Project, LHD Tidal current energy demonstration project started in 2014. It would install seven turbine modules (three turbines in $0.6 \mathrm{MW}$ and four turbines in $0.4 \mathrm{MW}$ ) in the $3.4 \mathrm{MW}$ assembly platform.

The assembly platform (size: $70 \mathrm{~m} \times 30 \mathrm{~m} \times 20 \mathrm{~m}$, weight: $2500 \mathrm{~T}$ ), "Scientist . Overseas Chinese Federation", was launched in the south of Xiushan Island, Daishan, Zhejiang Province on March 1, 2016 (see in Figure 29) [22,24]. The first set of 1MW power generation modules (height: $24 \mathrm{~m}$, weight: $230 \mathrm{~T}$ ), including $0.4 \mathrm{MW}$ and $0.6 \mathrm{MW}$ verticalaxis turbines with cut-in speed of $0.7 \mathrm{~m} / \mathrm{s}$ and cut-out speed of $4 \mathrm{~m} / \mathrm{s}$, were successfully installed on 27 July 2016 (see in Figure 30) [30,75,76]. These two are composed of two $300 \mathrm{~kW}$ and two $200 \mathrm{~kW}$ generators, respectively. On 15 August, this first set officially started to generate electricity, and successfully integrated into the power grid on 26 August. Since then, China's tidal current power generation entered "the megawatt era". China became the third country after the United Kingdom and the United States to master the technology of grid connection of TCPGS [23]. 

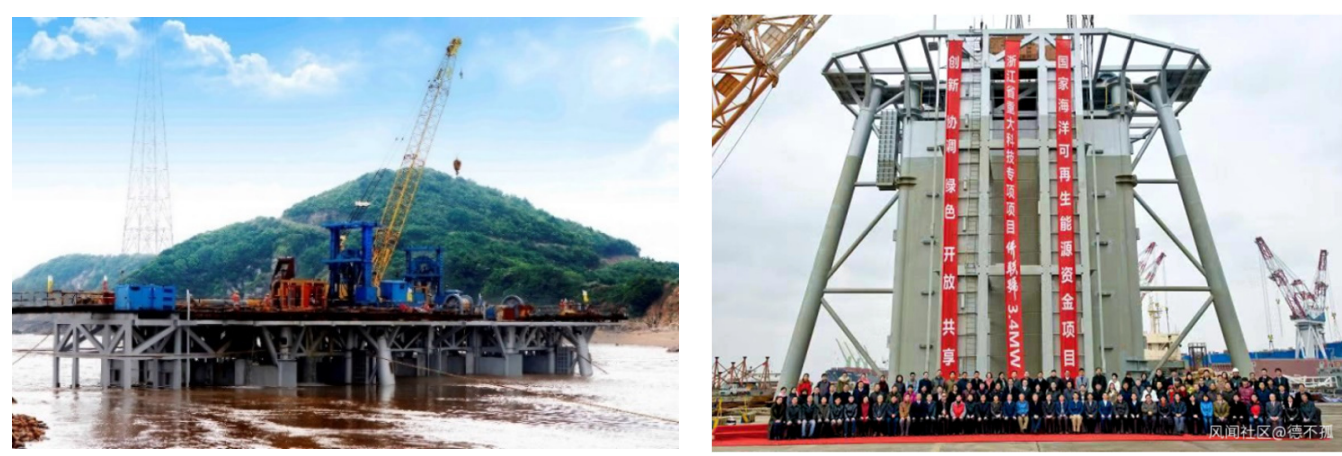

Figure 29. The assembly platform of the "3.4 MW LHD Modular Large-scale Tidal Power Generating Units". Reproduced from $[77,78]$.
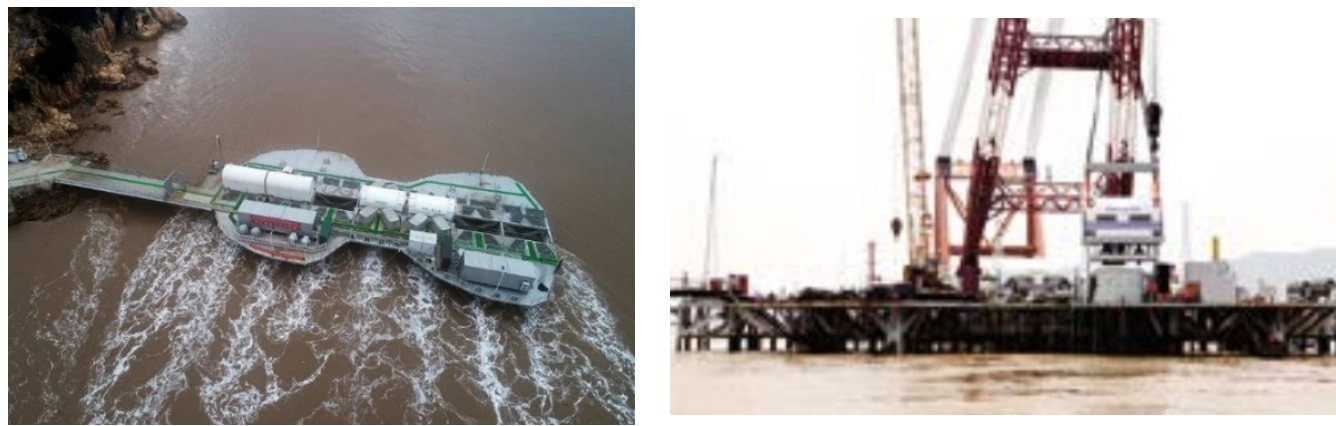

Figure 30. LHD 1 MW power generation module. Reproduced from $[79,80]$.

On 29 November 2018 and 29 December 2018, the second and third generation of the turbine modules ( $300 \mathrm{~kW}$ horizontal-axis F-module and $400 \mathrm{~kW}$ vertical-axis G-module) were also successfully launched in the platform (see in Figure 31). From then on, the total installed capacity of the 3.4 MW LHD project has reached 1.7 MW. From 2016 until October 2020, the demonstration project continuously operated for more than 40 months and had a cumulative power generation exceeding 1.95 GWh [81].

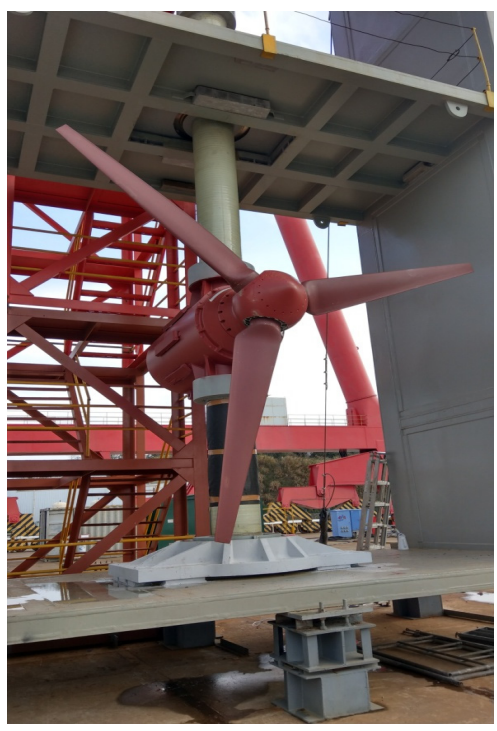

Figure 31. F-module by LHD and Blue Shark Power System, $300 \mathrm{~kW}$. Reproduced from [82]. 
In 2018, LHD was funded by the SFPMRE again, to press ahead with the next project phase, including the second assembly platform "Entrepreneur - Overseas Returnee" with 4.1 MW capacity and $1 \mathrm{MW}$ new turbine. By the end of 2020, the main structure of the second platform had been completed.

\subsection{HEC}

In 2010, HEC began a project of "Manufacturing of $600 \mathrm{~kW}$ Submarine TCPGS", which was sponsored by SFPMRE. Over the course of nearly 10 years, HEC made a series of innovations in the key technologies, such as the seal of the generator, anti-fouling, anticorrosion, transmission system and so on. The system is a catamaran structure that is $45 \mathrm{~m}$ in length, $20 \mathrm{~m}$ in width, and $400 \mathrm{~T}$ in displacement (see in Figure 32). The device was deployed for sea trail in the sea area of Zhairuoshan, Zhoushan, Zhejiang Province on 9 September 2019. According to the data, the total energy conversion efficiency was $37 \%$, and the starting flow velocity was only $0.51 \mathrm{~m} / \mathrm{s}$, which was the leading level in China [83].

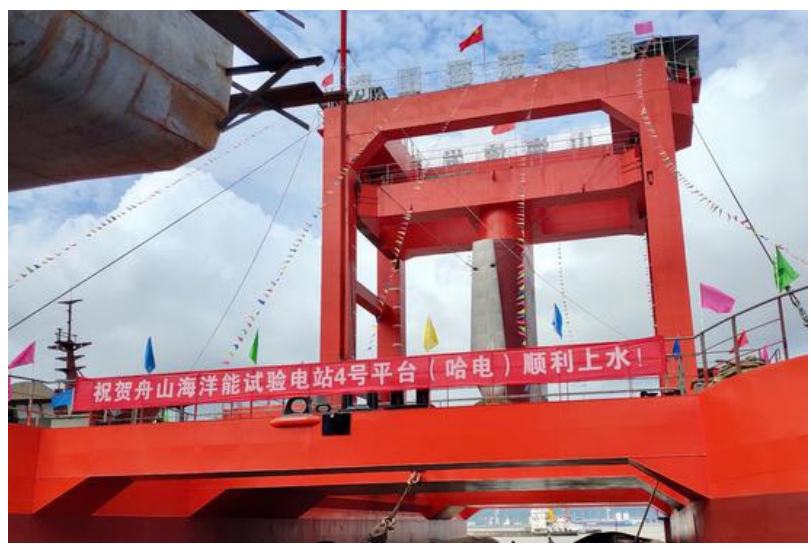

Figure 32. Ocean energy test platform for $600 \mathrm{~kW}$ Submarine TCPGS. Reproduced from [84].

\subsection{China Three Gorges Corporation}

Zhoushan tidal current energy demonstration project was developed by China Three Gorges Corporation (CTG) with the support of SFPMRE. It started in 2016 and completed the construction of $300 \mathrm{~kW}$ TCPGS in 2019. In April 2021, the offshore step-up station and $300 \mathrm{~kW}$ TCPGS had been installed near Hulu island (see in Figure 33). As part of the Zhoushan tidal current energy test site, the platform will be able to provide testing services for $3 \times 600 \mathrm{~kW}$ TCPGS. This test site will begin operation and provide test services in $2021[81,85]$.

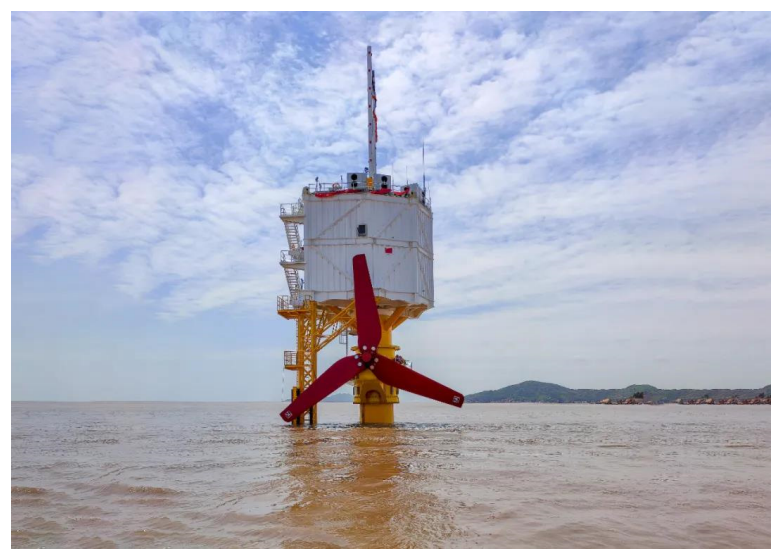

Figure 33. Offshore Step-up Station and $300 \mathrm{~kW}$ Turbine of CTG. Reproduced from [85]. 


\subsection{Institute of Electrical Engineering of Chinese Academy of Sciences}

In 2013, The Institute of Electrical Engineering of Chinese Academy of Sciences successfully developed the flange-driven TCPGS supported by SFPMRE (see in Figure 34). The system has a floating horizontal-axis turbine $(2 \times 2.5 \mathrm{~kW})$ installed on the platform $(36 \mathrm{~m} \times 8 \mathrm{~m} \times 2 \mathrm{~m})$. Since the system was put into trial in the sea near Xishan Island, Zhoushan, Zhejiang Province on 17 July 2016, it has operated successfully, without failure, for 17 months, and has had an average daily generation time of $11 \sim 13 \mathrm{~h}$, a comprehensive power generation efficiency of more than $40 \%$, and a starting flow velocity of $0.35 \mathrm{~m} / \mathrm{s}$. Later, the research group used the new motor to establish the power generation platform "Zhongke Haidian I", that had a total installed capacity of $15 \mathrm{~kW}$ (size: $36 \mathrm{~m} \times 8 \mathrm{~m} \times 2 \mathrm{~m}$ ), and was used to carry out a series of scientific research experiments [80,86].
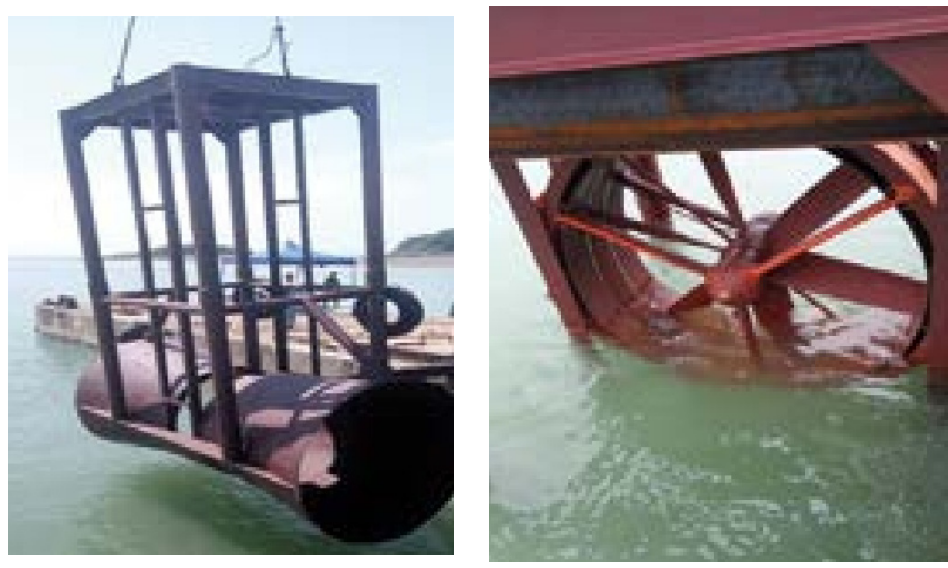

Figure 34. The flange-driven TCPGS. Reproduced from [80].

\subsection{NOTC}

Sponsored by SFPMRE, NOTC developed the floating test platform. In September 2019, it was deployed in the Weihai test site, which is an important part of the national open sea test site. From then on, it could provide open sea test services for small-scale horizontal-axis TCPGS and marine instruments, including power test system, monitoring systems, data communication systems, and comprehensive evaluation systems [81,87].

\subsection{Qingdao Haisizhuang Iron Tower Co., Ltd.}

On 21 December 2012, Qingdao Haisizhuang Iron Tower Co., Ltd. (Qindao, China) successfully developed a $10 \mathrm{~kW}$ horizontal-axis direct-drive TCPGS with PMSG. This is a project supported by SFPMRE since 2010. The blades of the device are made of carbon fibre nanomaterials. The designed flow velocity is $1.5 \mathrm{~m} / \mathrm{s}$. The sea trail was conducted in 2014. The device started to generate electricity when the flow velocity was between 0.6 and $1.3 \mathrm{~m} / \mathrm{s}$, and the energy conversion rate was greater than $30 \%$ [20,88].

\subsection{Others}

In addition to the above institutions, there are many other universities that have conducted lots of research work on TCPGS. In 2003, Tianjin university completed the design and experimental study of the runner part of a small underwater low-speed power generation device [18,46]. In 2011, Shanghai Maritime University, together with the University of Brest in France and the French Naval Academy, jointly developed a low-speed TCPGS, which is mainly used to study the control strategy and fault detection of small-scale TCPGS (see in Figure 35). Hohai University has studied a new type of high-efficiency bidirectional blade model for TCPGS, sponsored by MOST [18,32]. Shanghai Jiao Tong University researched on the project of the " $20 \mathrm{~kW}$ variable geometry turbine TCPGS" of SFPMRE from 2011, which is composed of a hydraulic pump with a digital distribution mechanism, a control device, a hydraulic motor and a generator $[18,46,89]$. In 2011, Ningbo 
Tech University developed "Independent power generation and seawater desalination system for islands based on tidal current energy and wave energy coupling" under the support of SFPMRE. The device is $14 \mathrm{~m}$ in length, $11 \mathrm{~m}$ in width and $4.5 \mathrm{~m}$ in height. It is a floating catamaran platform. The horizontal-axis tidal current capture device is placed in the middle, and a wave energy capture device is placed on both sides. The device was deployed for sea trial in June, 2013 and operated continuously for more than 20 months [20,90]. In June 2018, under the auspices of SOA, NOTC, China National Heavy Machinery Research Institute Co., Ltd. and Weihai Campus of Harbin Institute of technology jointly developed the pitch system, transmission system, hub, connecting device and the blade of the $150 \mathrm{~kW}$ TCPGS, which belonged to the project of "Research on technology of marine energy power generation and coupling technology of marine energy and seawater desalination" [91].
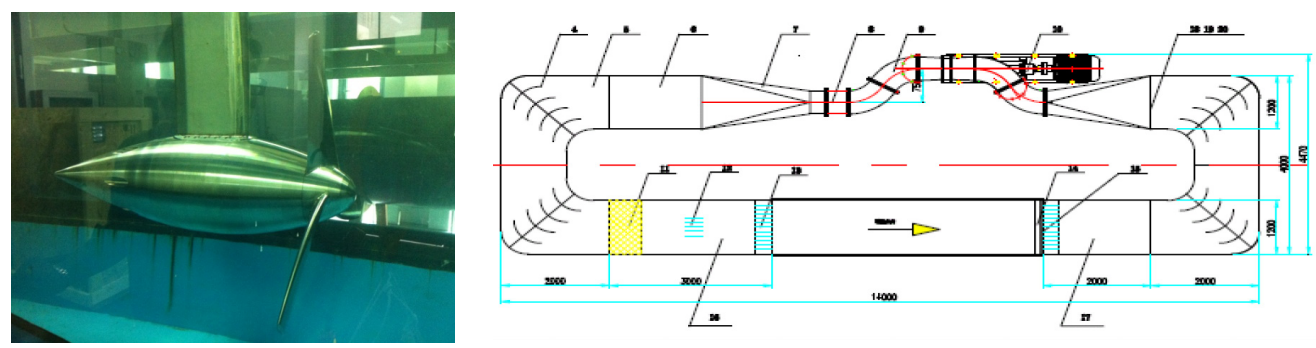

Figure 35. Experimental TCPGS developed by Shanghai Maritime University, University of Brest and French Naval Academy.

\section{Discussion}

According to the last section, obviously, the research in TCPGS is carried out by the universities under the support of the government. Many university and research institutes have invested in the early research.

HUE firstly realized vertical-axis power station and continued this technical route until 2013. The maximum power capacity is only $300 \mathrm{~kW}$. Although OUC, DUT and Shanghai Jiao Tong University also studied vertical-axis technology, there has been no relative information since 2015. Indeed, LDH applied vertical-axis modules in the 3.4 MW assembly platform, however, it also began to develop horizontal-axis technology since 2018. All this information implies that vertical-axis technology may be not quite suitable for tidal current power generation, at least in China, due to possible reasons, such as poor starting torque, more torque ripple, and lower efficiency, etc.

Horizontal-axis technology seems to be more interesting for the other research institutes. NENU and ZJU continued their research in this domain. They have developed series of technologies independently or cooperatively with other companies, and realized $300 \mathrm{~kW}$ and $650 \mathrm{~kW}$ prototypes, respectively. Right now, $650 \mathrm{~kW}$ is exactly the largest unit capacity of TCPGS in China.

Table 5 shows a comparison of studies on tidal current power generation in China and other countries.

It can be seen from the table that, first of all, the TCPGSs in other countries are mostly developed by enterprises. However, China's TCPGSs are generally concentrated in universities. With the passage of time and the maturity of technology, more and more enterprises in China have begun to participate, such as LHD, CTG and GDUP.

Secondly, due to different modes of research in different countries, the research institutes in China focus on the verification of different technologies. The prototypes are relatively small, mostly in the tens to hundreds of kilowatts. Foreign companies pay more attention to industrialization and commercialization of the technology with capacities ranging mainly from several hundred kilowatts to several megawatts. Until now, the biggest unit capacity of TCPGS in China is only $650 \mathrm{~kW}$, while it's already 1.5 MW for SIMEC Atlantis Energy and the system with $2 \mathrm{MW}$ is now under development. It is really difficult to evaluate the developments 
between China and other countries, as it also depends on the policies and resources of different countries. From this table, what should be mentioned is that in the last 5 years, many enterprises developed different prototypes successfully and passed the necessary tests in China. The next step is to think about the industrialization of these prototypes.

Thirdly, from this table, most the foreign companies also prefer the horizontal-axis technology. Some companies researched vertical-axis technology in the start stage, and later disappeared. Presently, the only companies who still focus on vertical-axis technology are Hydroquest in France and ORPC in Portland. The only information about their technologies is that TCPGS could all be composed of multiple modules and reach 2 MW capacity [93,94]. These technologies may be also very instructive for the Chinese researchers. However, the prototypes were all tested in Europe, where the tidal current speed is much higher than that in China. The possibility of adopting these technologies is still unknown and needs to be researched deeply.

Fourthly, most of TCPGSs in China use gearboxes, which may be associated with relatively low tidal current speeds in China. It is interesting that some large TCPGSs in other countries also adopt gearboxes. This is because the direct-drive tidal current generator has no gearbox and the turbine is directly connected with the generator, which leads to all kinds of harmful impact loads, which are borne by the generator system. Therefore, the requirements for the generator will be very high. If the direct-drive tidal current generator is adopted, the adopted drivetrain option will be more or less impacted by biofouling. Indeed, a full direct-drive TCPGS, which is associated with the low current speed, will typically have a large diameter generator with a large pole pair and volume, and the resulting big nacelle. Large dimension static parts will favour biofouling development.

In addition, compared with different systems with the similar power capacity in different countries, the systems in China always have larger turbine diameter due to the relatively low current speed. Indeed, the ducted structure could be used for speed amelioration. However, this structure is mainly used in vertical-axis technology, except for in rim-drive technology. Unfortunately, this structure would always be associated direct-drive generator and also results in biofouling problems, such as in the Openhydro turbine and Clean Current tidal turbine.

In a word, TCPGSs in China and other countries have many differences and similarities. Table 5 shows that both in China and other countries, as time goes by, more and more institutions participate in the study of tidal current power generation, and the installed capacity of TCPGSs increases year by year. This is related to the current theme of world development, "green, healthy and environmental protection", and also related to the policies of various countries.

The next five years is a critical period for the development of the international marine renewable energy industry. European and American countries and regions have supported the marine renewable energy industry as an important growth point of the blue economy. Right now, the MeyGen project of UK, with a power capacity of up to $398 \mathrm{MW}$, containing 269 submerged turbines, is the latest tidal farm project. The Tidal Stream Industry Energiser Project, known as TIGER, is the biggest ever Interreg project of the Interreg France (Channel) England Programme, costing EUR $45.4 \mathrm{~m}$. It aims to demonstrate that tidal current power generation is a maturing industry and could achieve an accelerated cost reduction pathway.

With the implementation of China's national strategy of "accelerating the construction of a maritime power", the marine renewable energy industry is expected to become an important potential field for China's energy structure adjustment and marine industry transformation and upgrading. It is very important to scientifically plan the development of the marine renewable energy industry in China.

China has entered the beginning of the 14th five-year plan and has put forward the vision goal of 2035, which aims to widely develop a green way of life and work; the ecological environment will be fundamentally improved, and carbon emissions will decrease after peaking. In order to achieve this plan and goal, in the next five years, China will increase investment in the new energy industry, focusing on increasing the proportion of non-fossil energy in China's energy supply structure, and providing funds and policies to support the development of tidal current energy utilization. 
Table 5. Comparison of tidal current power generation technologies between China and other countries $[1,56,92]$

\begin{tabular}{|c|c|c|c|c|c|c|c|c|c|c|c|}
\hline Name & Research Institutions & Country & Type & Capacity & Diameter & Date & Test Site & Variable- Pitch & with Gear Box & with Duct & Rated Velocity \\
\hline Clean Current Turbine & Clean Current & Canada & horizontal-axis & $65 \mathrm{~kW}$ & $6 \mathrm{~m}$ & 2006 & Race Rocks, Canada & No & No & Yes & \\
\hline Sabella D03 & SABELLA & France & horizontal-axis & $10 \mathrm{~kW}$ & $3 \mathrm{~m}$ & 2008 & $\begin{array}{l}\text { Odet's estuary in South } \\
\text { Brittany }\end{array}$ & No & No & No & \\
\hline Sabella D10 & SABELLA & France & horizontal-axis & $1 \mathrm{MW}$ & $10 \mathrm{~m}$ & 2015 & Ushant Island & No & No & No & $4 \mathrm{~m} / \mathrm{s}$ \\
\hline HyTide 1000 & Ocean Energies at Voith Hydro & German & horizontal-axis & $110 \mathrm{~kW}$ & $5.3 \mathrm{~m}$ & 2011 & Korea & & No & No & $2.9 \mathrm{~m} / \mathrm{s}$ \\
\hline HyTide 1000-16 & Ocean Energies at Voith Hydro & German & horizontal-axis & $1 \mathrm{MW}$ & $13-16 \mathrm{~m}$ & & & & No & No & $3.5 \mathrm{~m} / \mathrm{s}$ \\
\hline OpenCentre & OpenHydro & Ireland & horizontal-axis & $250 \mathrm{~kW}$ & $6 \mathrm{~m}$ & 2006 & EMEC & No & No & Yes & $1.5 \mathrm{~m} / \mathrm{s}$ \\
\hline Kobold & Insean & Italy & vertical-axis & $20 \mathrm{~kW}$ & $6 \mathrm{~m}$ & 2006 & & & Yes & No & $1.8 \mathrm{~m} / \mathrm{s}$ \\
\hline E-tide & Hammerfest Strom & Norway & horizontal-axis & $300 \mathrm{~kW}$ & $15-16 \mathrm{~m}$ & 2003 & $\begin{array}{l}\text { Kvalsund, Northern } \\
\text { Norway }\end{array}$ & Yes & & No & \\
\hline HS1000 & Andritz Hydro Hammerfest & Norway & horizontal-axis & $1 \mathrm{MW}$ & $23 \mathrm{~m}$ & 2011 & EMEC & & Yes & No & \\
\hline HS300 & Andritz Hydro Hammerfest & Norway & horizontal-axis & $300 \mathrm{~kW}$ & $10 \mathrm{~m}$ & 2003 & Kvalsunder, Norway & & & No & \\
\hline Seaflow & Atlantis Energy Ltd. (MCT) & UK & horizontal-axis & $300 \mathrm{~kW}$ & $11 \mathrm{~m}$ & 2003 & North Devon, UK & Yes & Yes & No & \\
\hline SeaGen S & $\begin{array}{l}\text { Atlantis Energy Ltd. (MCT) and } \\
\text { Bluewater }\end{array}$ & UK & horizontal-axis & $1 \times 2 \mathrm{MW}$ & $20 \mathrm{~m}$ & 2008 & $\begin{array}{l}\text { Strangford Lough, } \\
\text { Northern Ireland }\end{array}$ & Yes & Yes & No & $2.5 \mathrm{~m} / \mathrm{s}$ \\
\hline SeaGen U & Atlantis Energy Ltd. (MCT) & UK & horizontal-axis & $1.5 \mathrm{MW}$ & $20 \mathrm{~m}$ & & & & & No & \\
\hline SR2000 & Scotrenewables Tidal Power Ltd. & UK & horizontal-axis & $2 \mathrm{MW}$ & $20 \mathrm{~m}$ & 2016 & $\begin{array}{l}\text { Pentland Firth between the } \\
\text { North of Scotland and the } \\
\text { Orkney Islands }\end{array}$ & No & & No & $3 \mathrm{~m} / \mathrm{s}$ \\
\hline AR1000 & Atlantis Energy & UK & horizontal-axis & $1 \mathrm{MW}$ & $18 \mathrm{~m}$ & 2011 & $\begin{array}{l}\text { EMEC's Fall of Warness } \\
\text { tidal test site }\end{array}$ & No & Yes & No & $2.65 \mathrm{~m} / \mathrm{s}$ \\
\hline Deepgen & GE(TGL) & UK & horizontal-axis & $500 \mathrm{~kW}$ & & 2011 & EMEC & & & No & \\
\hline Wanxiang I & HUE & China & vertical-axis & $70 \mathrm{~kW}$ & $2.2 \mathrm{~m}$ & 2002 & $\underset{\text { Guishan Channel, Zhejiang }}{\text { Province }}$ & & Yes & No & $2.5 \mathrm{~m} / \mathrm{s}$ \\
\hline Wanxiang II & HUE & China & vertical-axis & $40 \mathrm{~kW}$ & & 2005 & $\begin{array}{c}\text { Xiaomentou Channel, } \\
\text { Zhejiang Province }\end{array}$ & & & & \\
\hline Haiming I & HUE & China & horizontal-axis & $10 \mathrm{~kW}$ & & 2011 & $\begin{array}{l}\text { Xiaomentou Channel, } \\
\text { Zhejiang Province }\end{array}$ & & No & Yes & $2 \mathrm{~m} / \mathrm{s}$ \\
\hline Haineng I & HUE & China & vertical-axis & $2 \times 150 \mathrm{~kW}$ & $4 \mathrm{~m}$ & 2012 & $\begin{array}{l}\text { Guishan Channel, Zhejiang } \\
\text { Province }\end{array}$ & Yes & No & No & \\
\hline Haineng II & HUE & China & horizontal-axis & $2 \times 100 \mathrm{~kW}$ & $12 \mathrm{~m}$ & 2013 & $\begin{array}{l}\text { Zhaitang Island, Shandong } \\
\text { Province }\end{array}$ & Yes & No & No & $1.7 \mathrm{~m} / \mathrm{s}$ \\
\hline Haineng III & HUE & China & vertical-axis & $2 \times 300 \mathrm{~kW}$ & $6 \mathrm{~m}$ & 2013 & $\begin{array}{l}\text { Guishan Channel, Zhejiang } \\
\text { Province }\end{array}$ & & Yes & No & $3 \mathrm{~m} / \mathrm{s}$ \\
\hline $2 \mathrm{~kW}$ TCPGS & NENU & China & horizontal-axis & $2 \mathrm{~kW}$ & & & $\begin{array}{l}\text { Qingdao, Shandong } \\
\text { Province }\end{array}$ & No & Yes & No & $0.9 \mathrm{~m} / \mathrm{s}$ \\
\hline $5 \mathrm{~kW}$ TCPGS & NENU & China & horizontal-axis & $5 \mathrm{~kW}$ & $2.6 \mathrm{~m}$ & 2014 & $\begin{array}{l}\text { Zhaitang Island Channel, } \\
\text { Shandong Province }\end{array}$ & No & No & No & $2.2 \mathrm{~m} / \mathrm{s}$ \\
\hline $15 \mathrm{~kW}$ TCPGS & NENU & China & horizontal-axis & $15 \mathrm{~kW}$ & & 2016 & $\begin{array}{l}\text { Zhaitang Island Channel, } \\
\text { Shandong Province }\end{array}$ & Yes & Yes & No & $2 \mathrm{~m} / \mathrm{s}$ \\
\hline $20 \mathrm{~kW}$ TCPGS & NENU & China & horizontal-axis & $20 \mathrm{~kW}$ & $5 \mathrm{~m}$ & 2013 & & No & No & No & $2.1 \mathrm{~m} / \mathrm{s}$ \\
\hline $300 \mathrm{~kW}$ TCPGS & NENU & China & horizontal-axis & $300 \mathrm{~kW}$ & $16.5 \mathrm{~m}$ & 2019 & $\begin{array}{l}\text { Zhoushan, Zhejiang } \\
\text { Province }\end{array}$ & Yes & & No & $2 \mathrm{~m} / \mathrm{s}$ \\
\hline
\end{tabular}


Table 5. Cont.

\begin{tabular}{|c|c|c|c|c|c|c|c|c|c|c|c|}
\hline Name & Research Institutions & Country & Type & Capacity & Diameter & Date & Test Site & Variable- Pitch & with Gear Box & with Duct & Rated Velocity \\
\hline $\begin{array}{l}\text { Power supply system for ocean } \\
\text { energy underwater instruments }\end{array}$ & NENU & China & horizontal-axis & $120 \mathrm{~W}$ & $1.8 \mathrm{~m}$ & 2019 & $\begin{array}{l}\text { Qingdao, Shandong } \\
\text { Province }\end{array}$ & No & Yes & No & \\
\hline Underwater Windmill & $\mathrm{zJU}$ & China & horizontal-axis & $5 \mathrm{~kW}$ & & 2006 & $\begin{array}{l}\text { Xiaomentou Channel, } \\
\text { Zhejiang Province }\end{array}$ & No & Yes & No & $1.7 \mathrm{~m} / \mathrm{s}$ \\
\hline $20 \mathrm{~kW}$ TCPGS & $\mathrm{zJU}$ & China & horizontal-axis & $20 \mathrm{~kW}$ & & 2010 & 1 & Yes & & No & \\
\hline $25 \mathrm{~kW}$ TCPGS & $\mathrm{zJU}$ & China & horizontal-axis & $25 \mathrm{~kW}$ & $4.4 \mathrm{~m}$ & 2009 & $\begin{array}{l}\text { Daishangang Channel, } \\
\text { Zhejiang Province }\end{array}$ & Yes & Yes & No & $2 \mathrm{~m} / \mathrm{s}$ \\
\hline $60 \mathrm{~kW}$ semi-direct-drive TCPGS & $\mathrm{zJU}$ & China & horizontal-axis & $60 \mathrm{~kW}$ & $7 \mathrm{~m}$ & 2014 & $\begin{array}{l}\text { Zhairuoshan, Zhejiang } \\
\text { Province }\end{array}$ & & Yes & No & $2 \mathrm{~m} / \mathrm{s}$ \\
\hline $2 \times 300 \mathrm{~kW}$ TCPGS & $\mathrm{zJU}$ & China & horizontal-axis & $300 \mathrm{~kW}$ & $15.5 \mathrm{~m}$ & 2018 & $\begin{array}{c}\text { Zhairuoshan, Zhejiang } \\
\text { Province }\end{array}$ & & Yes & No & $2 \mathrm{~m} / \mathrm{s}$ \\
\hline $650 \mathrm{~kW}$ semi-direct-drive TCPGS & $\mathrm{ZJU}$ & China & horizontal-axis & $650 \mathrm{~kW}$ & $15.45 \mathrm{~m}$ & 2017 & & Yes & Yes & No & $2.5 \mathrm{~m} / \mathrm{s}$ \\
\hline $5 \mathrm{~kW}$ flexible blade TCPGS & OUC & China & vertical-axis & $5 \mathrm{~kW}$ & & 2008 & $\begin{array}{l}\text { Zhaitang Island Channel, } \\
\text { Shandong Province }\end{array}$ & Yes & No & Yes & $1.7 \mathrm{~m} / \mathrm{s}$ \\
\hline Haichuan & ouc & China & horizontal-axis & $20 \mathrm{~kW}$ & $4.57 \mathrm{~m}$ & 2015 & $\begin{array}{l}\text { Zhaitang Island Channel, } \\
\text { Shandong Province }\end{array}$ & Yes & Yes & No & $1.7 \mathrm{~m} / \mathrm{s}$ \\
\hline $100 \mathrm{~kW}$ TCPGS & ouc & China & horizontal-axis & $100 \mathrm{~kW}$ & $10.5 \mathrm{~m}$ & 2013 & $\begin{array}{l}\text { Zhaitang Island Channel, } \\
\text { Shandong Province }\end{array}$ & Yes & Yes & No & $1.5 \mathrm{~m} / \mathrm{s}$ \\
\hline $15 \mathrm{~kW}$ direct-drive TCPGS & DUT & China & vertical-axis & $15 \mathrm{~kW}$ & $3.8 \mathrm{~m}$ & 2013 & $\begin{array}{l}\text { the channel between } \\
\text { Dachangshan and } \\
\text { Xaachangshan IIlands, } \\
\text { Liaoning Province }\end{array}$ & No & No & Yes & $1.3 \mathrm{~m} / \mathrm{s}$ \\
\hline $\begin{array}{l}\text { Scientist. Overseas Chinese } \\
\text { Federation }\end{array}$ & LHD & China & vertical-axis & $1.7 \mathrm{MW}$ & & 2018 & $\begin{array}{c}\text { Xiushan Island, Zhejiang } \\
\text { Province }\end{array}$ & & & & \\
\hline $300 \mathrm{~kW}$ Turbine & China Three Gorges Corporation & China & horizontal-axis & $300 \mathrm{~kW}$ & & 2021 & $\begin{array}{l}\text { Hulu Island, Zhejiang } \\
\text { Province }\end{array}$ & & & No & \\
\hline Flange-driven TCPGS & IEEACS & China & horizontal-axis & $2 \times 2.5 \mathrm{~kW}$ & & 2016 & $\begin{array}{l}\text { Xishan Island, Zhejiang } \\
\text { Province }\end{array}$ & & & Yes & \\
\hline
\end{tabular}




\section{Summary}

This paper first introduces the reserves and distribution of tidal current energy in China during the three national assessments, and then introduces the research on TCPGSs by various research institutions in China. Finally, the similarities and differences between China and other countries in tidal current power generation technology are compared, and the future development of tidal current power generation technology in China is prospected, based on China's current planning and goals.

As an important clean and renewable energy, tidal current energy is expected to supplement and replace oil, coal, natural gas, and other non-renewable energies in the future, and improves the situation of the greenhouse effect and environmental pollution. China, who has great potential in this aspect, should and must make some achievement in this field. During the last 20 years, with the finance of MNR and MOST, and the support of relevant national policies, the number of units participating in the research of TCPGS is gradually increasing. The types and quantity of the devices are also increasing, which makes the research on tidal current power generation technology and the manufacturing capacity of related equipment in China achieve rapid development and improvement. The construction of test platforms and demonstration projects in universities, research institutes and enterprises also provide strong support for the research of key technologies.

As the main power generation technology in China has entered the trial stage and accumulated some experience, the key technical problems of power generation have been basically solved, and the key components of the power generation unit have been basically localized. However, the technology of tidal current power generation in China is still in the demonstration and test stage, and there are still some problems, such as low efficiency, high cost and low power generation. There is still a long way to go for the commercialization, industrialization and large-scale of TCPGS, which still need the support of funds and policies. Considering the "emission peak" and "carbon neutrality" of China, it's very urgent to exploit tidal current energy. Therefore, it is quite necessary to continue to strengthen the research on key technologies to reduce the manufacturing cost, improve the ability to resist natural disasters and seawater corrosion, and improve the energy conversion efficiency and installed capacity under the stable operation condition. Looking into the future, tidal current energy is expected to become an important part of China's new energy supply, just as wind and solar energy will.

Author Contributions: Conceptualization, H.C., Q.L. and J.H.; methodology, Q.L.; software, H.C. and Q.L.; validation, H.C. and Q.L.; formal analysis, Q.L.; investigation, H.C. and Q.L.; resources, M.B. and N.A.-A.; data curation, H.C. and Q.L.; writing-original draft preparation, H.C. and Q.L.; writing-review and editing, H.C., Q.L., M.B., J.H. and N.A.-A.; visualization, M.B. and N.A.-A.; supervision, M.B. and N.A.-A.; project administration, H.C. and M.B.; funding acquisition, H.C. and M.B. All authors have read and agreed to the published version of the manuscript.

Funding: This research was funded by National Natural Science Foundation of China, China (Grant No. 61503242, 61673260), Ministry of Natural Resources of the People's Republic of China (1941STC41744), Shanghai Science and Technology Commission project (Grant No. 20040501200), Science \& Technology Commission of Shanghai Municipality and Shanghai Engineering Research Centre of Ship Intelligent Maintenance and Energy Efficiency under Grant 20DZ2252300.

Institutional Review Board Statement: Not applicable.

Informed Consent Statement: Not applicable.

Data Availability Statement: The data that support the findings of this study are available within the article.

Acknowledgments: The authors acknowledge the Research Institute of Power Drive and Control of Shanghai Maritime University, Institut de Recherche en Energie Electrique de Nantes Atlantique of University of Nantes and UMR CNRS 6027 IRDL of University of Brest.

Conflicts of Interest: The authors declare no conflict of interest. 


\section{References}

1. Chen, H.; Tang, T.; Aït-Ahmed, N.; Benbouzid, M.; Machmoum, M.; Zaïm, M. Attraction, challenge and current status of marine current energy. IEEE Access 2018, 6, 12665-12685. [CrossRef]

2. Zhu, W.; Wu, B.; Zhao, Y.; Chen, J.; Dong, Y.; Zhang, X. Experimental Study on the Electric Supplementary Device Rated 2.5 kW for Marine Observation Instrument. Mar. Technol. Soc. J. 2016, 35, 41-44.

3. Zhou, Z.; Benbouzid, M.; Charpentier, J.F.; Scuiller, F.; Tang, T. Developments in large marine current turbine technologies-A review. Renew. Sust. Energy Rev. 2017, 71, 852-858. [CrossRef]

4. Xia, H. Research on Power Performance Testing and Analyzing Method of Electricity Producing Tidal Energy Converter. Master's Thesis, Dalian Ocean University, Dalian, China, 2015.

5. Zhang, L.; Li, X.; Geng, J.; Zhang, X. Tidal Current Energy Update 2013. Adv. New Renew. Energy 2013, 1, 53-68.

6. Liu, H.; Ma, S.; Li, W.; Gu, H.; Lin, Y.; Sun, X. A review on the development of tidal current energy in China. Renew. Sustain. Energy Rev. 2011, 15, 1141-1146. [CrossRef]

7. Li, D.; Wang, S.; Yuan, P. An overview of development of tidal current in china: Energy resource, conversion technology and opportunities. Renew. Sustain. Energy Rev. 2010, 14, 2896-2905. [CrossRef]

8. Liu, H.; Bahaj, A. Status of Marine Current Energy Conversion in China. Int. Mar. Energy J. 2021, 4, 11-23. [CrossRef]

9. Bai, Y.; Du, M.; Zhou, Q.; Meng, J.; Wu, H. Proceeding of Tidal Current Energy Conversion System. Ocean Dev. Manag. 2016, 33, 57-63.

10. Liu, Y.; Li, Y.; He, F.; Wang, H. Comparison study of tidal stream and wave energy technology development between China and some Western Countries. Renew. Sustain. Energy Rev. 2017, 76, 701-716. [CrossRef]

11. Liu, X.; Chen, Z.; Si, Y.; Qian, P.; Wu, H.; Cui, L.; Zhang, D. A review of tidal current energy resource assessment in China. Renew. Sustain. Energy Rev. 2021, 145, 111012. [CrossRef]

12. Guan, C. Concept Design and Performance Study of Floating Tidal and Wind Power Station. Master's Thesis, Harbin Engineering University, Harbin, China, 2015.

13. Overview of Ocean Energy. Available online: https://www.doc88.com/p-2942374039404.html (accessed on 25 September 2021).

14. Zhang, L.; Li, Z. Development Status, Trend and the Problems of Mechanics of Tidal Current Energy. Chin. J. Theor. Appl. Mech. 2016, 48, 1019-1032.

15. You, Y.; Li, W.; Liu, W.; Li, X.; Wu, F. Development Status and Perspective of Marine Energy Conversion Systems. Autom. Electr. Power Syst. 2010, 34, 1-12.

16. Bai, Y.; Hou, E.; Du, M. Research progress of tidal current power generation devices. In Proceedings of the China Marine Re-newable Energy Development Annual Conference and Forum, Guangdong, China, 25-26 May 2015.

17. Zhang, X. The Study of Con-horizontal Tidal Current Self-Pitch Turbine with Dual Rator. Ph.D. Thesis, Northeast Normal University, Changchun, China, 2013.

18. Gu, Y. Study on the Key Technologies of the Grid-connected Marine Current Turbine's Control System. Ph.D. Thesis, Zhejiang University, Hangzhou, China, 2018.

19. Zhang, Y.; Lin, Z.; Liu, Q. Marine renewable energy in China: Current status and perspectives. Water Sci. Eng. $2014,7,288-305$.

20. Hu, G. Two-dimensional Numerical Simulation of Vertical Current Turbine's Hydrodynamic Performance. Master's Thesis, Ocean University of China, Qingdao, China, 2015.

21. Zheng, J.; Dai, P.; Zhang, J. Tidal Stream Energy in China. Procedia Eng. 2015, 116, 880-887. [CrossRef]

22. Liu, Y.; Ma, C.; Jiang, B. Development and the environmental impact analysis of tidal current energy turbines in China. In Proceedings of the IOP Conference Series: Earth and Environmental Science; IOP Publishing Ltd.: Bristol, UK, 2018; Volume 121, p. 2003.

23. Hu, T. Research on the Influence of Blade Profile Precision on Tidal Turbine Airfoils. Master's Thesis, National Ocean Technology Center, Tianjin, China, 2019.

24. Wang, F. Design and Method Research of Pile Foundations for Tidal Current Power Generator Device. Master's Thesis, North China Electric Power University, Beijing, China, 2018.

25. Ana, B.M.; José, L.V. Country Reports. In Annual Report: Implementing Agreement on Ocean Energy Systems; The Executive Committee of Ocean Energy Systems: Paris, France, 2013; p. 127.

26. Wu, B. Research on the Horizontal Axis Tidal Stream Turbine. Ph.D. Thesis, Northeast Normal University, Changchun, China, 2015.

27. Li, T. Coupling Hydrodynamic Analysis of Vertical Axis Dual Rotor Floating Tidal Current Generator. Master's Thesis, Harbin Engineering University, Harbin, China, 2017.

28. Cheng, S. Research on the Influence of Duct on the Performance of Vertical Axis Tidal Turbine. Master's Thesis, Dalian University of Technology, Dalian, China, 2017.

29. Gao, W. Study on Hydrodynamic Performance of Self-adapt Floating Tidal Current Energy Generating Device. Master's Thesis, Ocean University of China, Qingdao, China, 2014.

30. Ana, B.M.; José, L.V. International Activities on Ocean Energy. In Annual Report: Ocean Energy Systems 2015; The Executive Committee of Ocean Energy Systems: Paris, France, 2015; p. 61.

31. Lu, L. Experimental Study on Hydrodynamic Performances of Flexible Blade Turbine Driven by Tidal Energy. Master's Thesis, Ocean University of China, Qingdao, China, 2009.

32. Li, B.; Li, L.; Yang, L.; Yang, X.; Xiao, Y. Utilization and research status of tidal current energy. Sol. Energy 2010, 9, 39-42. 
33. Ding, X. Research on the Variable Pitch Control of the Tidal Current Turbines. Master's Thesis, Harbin Engineering University, Harbin, China, 2015.

34. Zhu, W.; Xu, M.; Zhang, M. Study on the Key Technologies of Horizontal Axis Surface Tidal Current Generating. Acta Energ. Sol. Sin. 2012, 33, 1067-1072.

35. Chen, J.; Wu, B.; Zhu, W.; Xu, M.; Dong, Y.; Zhang, X. Design and Research of Passive Adaptive Bidirectional Flow Blade for Horizontal Axis Tidal Current Energy. Acta Energ. Sol. Sin. 2018, 39, 3295-3301.

36. Special Fund Project of State Oceanic Administration-300 kW Horizontal Axis Tidal Current Generator Set. Available online: http:/ / www.hjhe.cn/abc/ (accessed on 25 September 2021).

37. Dong, Y.; Guo, J.; Chen, J.; Sun, C.; Zhu, W.; Chen, L.; Zhang, X. Development of a 300 kW horizontal-axis tidal stream energy conversion system with adaptive variable-pitch turbine and direct-drive PMSG. Energy 2021, 226, 120361. [CrossRef]

38. Innovation Road of Zhejiang Hydropower People-Tidal Current Power Generation. Available online: http://kjb.zjol.com.cn/ html/2019-09/17/content_2680821.htm?div=-1 (accessed on 25 September 2021).

39. Power Supply System for Underwater Marine Instruments. Available online: http:/ /www.hjhe.cn/abc/show.php?lang=cn\&id=272 (accessed on 25 September 2021).

40. Major Scientific Research Project of Oceanic Administration-Successful Grid Connection of 300 kW Horizontal Axis Tidal Current Energy Generator Set. Available online: http:/ / www.hjhe.cn/abc/show.php?lang=cn\&id=272 (accessed on 25 September 2021).

41. Our School Has Made Great Progress in the Field of Marine Instrument Power Supply. Available online: http:/ / www.nenu.edu. cn/info/1055/12910.htm (accessed on 25 September 2021).

42. Wang, S. Study on Hydrodynamic Performances of a Tidal Current Energy Conversion Device with Flexible Blade Turbine. Ph.D. Thesis, Ocean University of China, Qingdao, China, 2009.

43. Liu, H.; Li, W.; Lin, Y.; Ma, S. Model Analysis and Test Research of Horizontal-axial Marine Current Turbine. Acta Energ. Sol. Sin. 2009, 30, 633-638.

44. Lin, Y.; Li, W.; Liu, H.; Ma, S. Ocean Current Power Generation Technology for Underwater Turbine. J. Zhejiang Univ. (Eng. Sci.) 2008, 42, 1242-1246.

45. Li, W.; Lin, Y.; Liu, H.; Ma, S. Research on ocean current energy generation technology of horizontal shaft propeller. In Proceedings of the Inaugural Meeting and the First Symposium of Ocean Energy Professional Committee of China Renewable Energy Society, Hangzhou, China, 27-28 March 2008.

46. Xu, Q. Research on Load Analysis and Control for Horizontal Axis Marine Current Turbine. Ph.D. Thesis, Zhejiang University, Zhejiang, China, 2015.

47. Yang, J. Study on Hydraulic Drive and Pitching System of Horizontal Axis Tidal Current Turbine. Master's Thesis, Zhejiang University, Hangzhou, China, 2017.

48. Ma, S.; Li, W.; Liu, H.; Lin, Y. Design and Experiment of an Electro-hydraulic Proportional Variable Pitch Control System for Tidal Current Turbines. Autom. Electr. Power Syst. 2010, 34, 86-90.

49. Liu, H.; Li, W.; Lin, Y.; Ma, S. Tidal current turbine based on hydraulic transmission system. J. Zhejiang Univ.-SCIENCE A (Appl. Phys. Eng.) 2011, 12, 511-518. [CrossRef]

50. Ma, S.; Li, W.; Liu, H.; Lin, Y. Research on the Energy Capture Device of Horizontal Axis Tidal Current Energy Conversion Systems. J. Mech. Eng. 2010, 46, 150-156. [CrossRef]

51. Lei, C. Study on Characteristics of Marine Current Turbine with Co-horizontal Axis and Double Impellers. Master's Thesis, North China Electric Power University, Beijing, China, 2016.

52. Ma, S.; Li, W.; Liu, H.; Lin, Y. A 25 kW Stand-alone Horizontal Axis Tidal Current Turbine. Autom. Electr. Power Syst. 2010, $34,18-22$.

53. Xu, Q.; Li, W.; Lin, Y.; Liu, H.; Gu, Y. Investigation of the performance of a stand-alone horizontal axis tidal current turbine based on in situ experiment. Ocean. Eng. 2016, 113, 111-120. [CrossRef]

54. Xu, Q.; Liu, H.; Lin, Y.; Yin, X.; Li, W.; Gu, Y. Development and experiment of a $60 \mathrm{~kW}$ horizontal-axis marine current power system. Energy 2015, 88, 149-156. [CrossRef]

55. Li, W.; Liu, H.; Lin, Y.; Zhou, H.; Gu, Y.; Xu, Q. Offshore test of 60kW horizontal axis tidal current generator set. In Proceedings of the 4th China Annual Conference and Forum on Marine Renewable Energy Development, Weihai, China, 28 May 2015.

56. Touimi, K.; Benbouzid, M.; Tavner, P. Tidal stream turbines: With or without a Gearbox? Ocean. Eng. 2018, 170, 74-88. [CrossRef]

57. Liu, Y.; Wang, H.; Wang, J.; Chen, L.; Sun, Y.; Zhang, R.; Tang, J. Utilization Status and Suggestions on Development of Tidal Current Energy in Zhoushan Area. Ocean. Dev. Manag. 2016, 33, 77-79.

58. Jia, F.; Chu, J.; Yuan, L.; Wang, T. Research and development on the safety system for tidal current energy turbine. Renew. Energy Resour. 2020, 38, 1693-1697.

59. World Leader! United Power 300kW Tidal Current Energy Generator Set Realizes Safe and Fault-Free Operation for Three months. Available online: https:/ / www.sohu.com/a/246401200_472920 (accessed on 25 September 2021).

60. Gu, Y.; Liu, H.; Li, W.; Lin, Y.; Li, Y. Integrated design and implementation of 120-kW horizontal-axis tidal current energy conversion system. Ocean. Eng. 2018, 158, 338-349. [CrossRef]

61. Li, Y.; Liu, H.; Lin, Y.; Li, W.; Gu, Y. Design and test of a 600-kW horizontal-axis tidal current turbine. Energy 2019, 182, 177-186. [CrossRef] 
62. High Efficiency Horizontal-Axis $650 \mathrm{~kW}$ Ocean Current Energy Generator Set Rerun after Optimization-Maximum Single Power. Available online: http:/ / me.zju.edu.cn/mecn/2020/0119/c6200a1957587/page.htm (accessed on 25 September 2021).

63. Ana, B.M.; Henry, J. International Activities. In Annual Report: An Overview of Ocean Energy Activities in 2017; The Executive Committee of Ocean Energy Systems: Paris, France, 2017; p. 59.

64. Ma, S. Study on Energy Conversion Efficiency and Power Control of Horizontal Axis Tidal Current Energy Conversion Systems. Ph.D. Thesis, Zhejiang University, Hangzhou, China, 2011.

65. Zhao, L.; Wang, S.; Li, D. The Status and Trends of Marine Current Energy Conversion in the World. In Proceedings of the second National Symposium on Ocean Energy, Harbin, China, 17-18 September 2009.

66. Guo, W. Numerical and Experiment Studies on a Novel Vertical-axis Tidal Current Energy Conversion Device. Ph.D. Thesis, Dalian University of Technology, Dalian, China, 2014.

67. Zhang, P. Investigation of the Structural Dynamic Response for Vertical-axis Tidal Current Turbine. Master's Thesis, Shanghai Jiao Tong University, Shanghai, China, 2017.

68. Li, J.; Wang, S.; Si, X.; Yuan, P. The numerical simulation of hydrodynamic performance of horizontal axis tidal current energy turbine under effect of linear wave. Renew. Energy Resour. 2017, 35, 1732-1738.

69. Tan, J.; Yan, J.; Wang, S.; Chen, Z.; Yuan, P. Energy capture analysis and application of tidal turbine with electric pitch control system. Ocean. Eng. 2017, 35, 70-75.

70. Wang, S.; Yu, X.; Li, R.; Yuan, P.; Zhang, Y. Research on the Effect of Buoyancy Carrier on the Performance of Tidal Current Energy Turbine. J. Ocean. Technol. 2016, 35, 5-9.

71. Xie, Y. Research and Experiments on the Hydrodynamic Performance of Vertical Axis Tidal Current Turbine. Ph.D. Thesis, Dalian University of Technology, Dalian, China, 2016.

72. Xie, Y.; Kang, H.; Chen, B.; Guo, W. Field test of a coaxial dual rotor vertical axis turbine. Proc. Inst. Mech. Eng. Part M J. Eng. Marit. Environ. 2018, 232, 253-260. [CrossRef]

73. Progress and Prospect of Marine Energy Technology in China. Available online: http://aoc.ouc.edu.cn/32/a5/c9821a209573/ page.psp (accessed on 25 September 2021).

74. The Megawatt Large-Scale Marine Tidal Current Energy Generator Set Assembly Platform Was Successfully Launched into the Sea in Zhoushan. Available online: http:/ / www.lhd-tech.com/lhd/news_view.php?nid=267 (accessed on 25 September 2021).

75. Liu, W.; Ma, C.; Chen, F.; Liu, L.; Ge, Y.; Peng, J.; Wu, H.; Wang, Q. Exploitation and Technical Progress of Marine Renewable Energy. Adv. Mar. Sci. 2018, 36, 1-18.

76. Wang, X.; Jia, N.; Xia, H.; Zhang, Y.; Guo, Y.; Wang, Z.; Yu, Y. Testing and Evaluation of China's Marine Energy Generating Devices. Ocean. Dev. Manag. 2018, 35, 87-90.

77. Research and Development Frontier of Marine Current Energy Advanced Power Generation Technology at Home and Abroad. Available online: www.lhd-tech.com/lhd/news_view.php?nid=282 (accessed on 25 September 2021).

78. The World's Only Marine Tidal Current Power Station: China Original! Let the Melody of the Sea Generate Electricity. Available online: https: / / user.guancha.cn/main/content?id=220433 (accessed on 25 September 2021).

79. The Entrepreneurial Story of Lin Dong, an Entrepreneurial Mentor in Our School-The Melody of Progress, a CCTV Blockbuster. Available online: https://www.sohu.com/a/376106961_467445 (accessed on 25 September 2021).

80. Ana, B.M.; José, L.V. International Activities on Ocean Energy. In Annual Report: Ocean Energy Systems 2016; The Executive Committee of Ocean Energy Systems: Paris, France, 2016; p. 71.

81. Ana, B.M. International Activities on Ocean Energy. In Annual Report: An Overview of Ocean Energy Activities in 2020; The Executive Committee of Ocean Energy Systems: Paris, France, 2020; p. 72.

82. The National Ocean Technology Center Completed the Field Test, Analysis and Evaluation of the Tidal Current Power Generation Device Jointly Developed by China and France. Available online: www.notcsoa.org.cn/cn/index/show/2649 (accessed on 25 September 2021).

83. Successful Development of Maximum Tidal Energy Generator Set in China. Available online: http://scitech.people.com.cn/n1/2 020/0114/c1007-31546598.html (accessed on 25 September 2021).

84. China Develops Large Tidal Current Generator Unit. Available online: http://www.xinhuanet.com/english/2020-01/14/c_1387 04813.htm (accessed on 25 September 2021).

85. Trial Operation of the First Public Welfare Open Tidal Current Energy Test Site in China. Available online: http:/ /www.sasac.gov. cn/n2588025/n2588124/c15129609/content.html (accessed on 25 September 2021).

86. The Flange-Driven TCPGS Developed by the Institute of Electrical Engineering Was Selected by OES as One of the New Developments in China's Ocean Energy Development and Utilization in 2016. Available online: http://www.bjb.cas.cn/djdt201 6/201711/t20171129_4901137.html (accessed on 25 September 2021).

87. Ana, B.M.; Henry, J. International Activities on Ocean Energy. In Annual Report: An Overview of Ocean Energy Activities in 2019; The Executive Committee of Ocean Energy Systems: Paris, France, 2019; p. 62. 
88. Ji, M. China's first marine tidal current power generation equipment came out. Dual Use Technol. Prod. $2013,1,45$.

89. Wang, Q.; Yang, B.; Lawn, C. Hydrodynamic research on VGT for marine current generation. Acta Energ. Sol. Sin. 2014, $35,1369-1374$.

90. The First Special Fund Project of Marine Renewable Energy in Ningbo Undertaken by Ningbo Tech University of Zhejiang University Has Achieved Phased Results. Available online: http://www.huaue.com/dlxy/2013923160939.htm (accessed on 25 September 2021).

91. Research and Development of $150 \mathrm{~kW}$ Tidal Current Power Generation Device by the National Ocean Technology Center Has Achieved Phased Results. Available online: http://notcsoa.org.cn/cn/index/show/1903 (accessed on 25 September 2021).

92. Zhou, Z.; Mohamed, B.; Charpentier, J.; Scuiiier, F.; Tang, T. Developments in large marine current turbine technologies-A review. Renew. Sustain. Energy Rev. 2017, 71, 852-858. [CrossRef]

93. Our Technologies, Tidal Power. Available online: https:/ /www.hydroquest.fr/en/tidal-power/ (accessed on 3 November 2021).

94. Turbine Generator Unit. Available online: https:/ / orpc.co/our-solutions/turbine-generator-unit (accessed on 3 November 2021). 